\title{
A Correction for Classic Performance Measures*
}

\author{
Hayette Gatfaoui \\ Rouen Business School, Mont-Saint-Aignan, France
}

\begin{abstract}
Non-normality in asset returns is now a common feature of financial markets. However, many practitioners as well as investors do still refer to classic risk adjusted performance measures to assess their investment. For example, Sharpe and Treynor ratios are designed for a Gaussian world. Then, employing them for a performance assessment prospect relative to the risk borne is a biased approach. If we look for consistency in risk assessment and in asset performance valuation, we need to look for robust methods or tools. Moreover, the well-known mathematical consistency and numerical tractability concerns drive our preference for simple methods. Under this setting, we propose to account in a simple way and to some extent for the skewness and kurtosis patterns describing the deviations from normality. We adjust therefore the classic Sharpe and Treynor ratios to asymmetries in the downside and upside deviations from the mean values of asset returns. Specifically, the adjusted Sharpe and Treynor ratios are weighted by the upside and downside deviation risks. Accounting for skewness and kurtosis changes generally the ranking of hedge fund performance. Moreover, the obtained adjusted performance measures capture well the skewness and/or kurtosis patterns in hedge fund returns depending on the targeted investment strategy.
\end{abstract}

Keywords: hedge fund, kurtosis, performance, Sharpe ratio, skewness, Treynor ratio

\section{Introduction}

At the beginning of 2008, the amount of hedge fund industry assets was around $\$ 2.65$ trillion while 390 firms where running 78.61\% of this amount (Hedge Fund Intelligence, 2008). Moreover, Credit Suisse/Tremont reported an average 12.56\% return for the hedge fund industry during year 2007 (Reuters, 2008). ${ }^{1}$ However, the previous performance profile has a cost despite the attractiveness of such investment vehicles. Indeed, it implies to bear some non-negligible risk levels, which have to be cautiously considered. Recent market history sheds light on the asymmetry in asset returns (i.e., asymmetry between potential gains and losses) as well as the significant correlation risk in and between asset classes during the subprime crisis. At this time, market volatility was very high, and though time has elapsed, volatility does still persist today. Common practice tells that an

\footnotetext{
*Acknowledgements: We would like to thank the participants at the 21st AFBC conference (December 2008, Sydney, Australia) and the Eastern Finance Association Annual Meeting (April-May 2009, Washington) for their helpful comments and remarks. We apologize for any missing reference. The usual disclaimer applies.

Hayette Gatfaoui, Ph.D., Accredited for Research and Ph.D. supervision, Economics and Finance Department, Rouen Business School.

Correspondence to this article should be addressed to Hayette Gatfaoui, 1 rue du Maréchal Juin, BP215, 76825 Mont-Saint-Aignan, Cedex, France. E-mail: hgt@rouenbs.fr; hgatfaoui@gmail.com.

1 The reported number of hedge funds and fund of funds is approximately 10,000 in 2007 (Source: Hedge Fund Research Inc., HFR industry report 2008), the number of hedge funds being around 9,000 (Source: Eureka Hedge).
} 
increase in volatility translates into an increase in surrounding uncertainty. This scenario means higher possible gains as well as higher possible losses for market participants. Consequently, high levels of potential profits have to be balanced with high risk levels (e.g., high volatility) and corresponding possible losses (e.g., failures of hedge funds such as LTCM in 1998 and Amaranth in 2006).

Such a setup launched the debate concerning the use of appropriate comparable data for measuring performance and appropriate comparable performance measures. First, comparability concerns yielded the use of risk-adjusted performance measures such as Sharpe and Treynor indexes among others (Sharpe, 1966; Treynor, 1965). Such classic performance measures are founded on a Gaussian return assumption and a mean-variance efficient world. Second, assessing soundly hedge fund performance, and in a more general way, performance requires to consider true performance proxies. It is then common thought to use raw returns as performance measures. Returns usually reflect the hedge fund manager's skills in terms of management and investment/trading strategy (i.e., hedge fund style). For this reason, using raw returns is not recommended since returns encompass fees such as management and incentive fees, and operating costs among others, and usually provide a too short performance history (Baquero, Horst, \& Verbeek, 2005; Horst \& Verbeek, 2007; Ibbotson \& Chen, 2005; Kat \& Menexe, 2003; Lavine, 2003; Liang, 2003; Weisman, 2002; Weisman \& Abernathy, 2000). ${ }^{2}$ Raw returns engender usually upward biased performance measures since existing fees tend to skew to the right related performance measures. This main drawback advocates then the use of net-of-fees returns, namely returns that are computed after excluding all possible fees. In that way, net returns represent a real performance proxy for hedge funds and illustrate also related managers' skills (Wermers, 2000). Finally, asset returns, and more specifically hedge fund returns often violate the Gaussian assumption (Eling, 2006; Madan \& McPhail, 2000; Taleb, 2007). Indeed, hedge fund strategies' returns are known to exhibit skewness and kurtosis patterns (Black, 2006; Eling \& Schuhmacher, 2006). Therefore, comparability concerns engender a need for sound and reliable performance measures, which account for skewness at least, and kurtosis when it is possible.

Our work brings a major value added to hedge fund performance practice while adjusting some well-known performance measures for skewness and, to some extent, for kurtosis concerns. Namely, we focus on two classical performance measures such as Sharpe and Treynor indexes, which are of high significance to investors, portfolio managers and market participants. Apart from considering historical returns' mean, such performance measures are free of ad hoc computations such as the choice of a specific probability distribution and a specific quantile level for example. ${ }^{3}$ However, Sharpe and Treynor ratios are biased (Klemkosky, 1973; Benefield,

\footnotetext{
${ }^{2}$ The authors point out the non-exhaustive pattern of historical data to assess future possible asset behaviors or performance (i.e., data length and accuracy, incomplete information content, insufficient information content of performance track records, or equivalently short performance history) as well as related short volatility, illiquid, self-reporting and look-ahead biases. Moreover, data are highly heterogeneous as a result of the optional nature of hedge fund strategies and investment styles. To bypass this shortcoming, Weisman and Abernathy (2000) propose a factor-based non-parametric performance analysis (i.e., generic model decomposition), which is less sensitive to non-exhaustive data, and which allows for extrapolating hedge fund performance over various market scenarios. Differently, Jones (2007) shows that certain qualitative aspects of hedge fund returns (e.g., size and age) explain their respective performance. For example, small funds outperform larger funds (but also exhibit higher volatility profiles) whereas the youngest funds outperform older funds.

${ }^{3}$ Indeed, it is often very hard to compare a 5\% student-based quantile with a 5\% Gumbel- or Weibull-based quantile. The nature and shape of the potential loss profile and downside risk related to two distinct probability distributions are quite different and not so easily comparable. It is significant to notice that yesterday's extreme return levels are far different from today's extreme return levels. Such features stem from the changing nature of risk structures.
} 
Anderson, \& Zumpano, 2007). We propose therefore an adjustment to offset such biases and to make Sharpe and Treynor indexes less sensitive to the presence of skewness and kurtosis effects in asset returns.

Our paper is organized as follows. Section 2 introduces the data set under consideration as well as related statistical properties and heterogeneity features. As the cornerstone of our paper, section 3 proposes a correction for two well-known and acknowledged classic performance measures while section 4 handles the straightforward corresponding numerical application. Finally, section 5 draws concluding remarks and possible future research extensions.

\section{Data}

We introduce our data set, which is composed of both benchmark indexes and other relevant market data.

\section{Data Set}

We consider two distinct sets of daily return data ${ }^{4}$ ranging from January 3, 2005 to February 22, 2008, namely a total of 790 observations per series. Returns are computed as the relative changes from one day to another, and expressed in percent. The first set of data refers to hedge fund benchmarks whereas the second set of data refers to equity and both corporate and treasury bond markets. Those two bullets of data present specific statistical features.

Dow Jones hedge fund indexes. The first set of data is provided by Dow Jones \& Company Inc., and corresponds to six Dow Jones Hedge Fund Strategy Benchmarks Indexes (DJHFSBIs) illustrating six style-pure strategies on one side, ${ }^{5}$ and three Dow Jones Hedge Fund Balanced Portfolio indexes (DJHFBPIs) illustrating three specific mixed portfolio strategies on the other side. Style-pure indexes are designed to track hedge funds' performance based on single-strategy considerations. They focus on six possible strategies, which are convertible arbitrage (DJHFSB_CA), distressed securities (DJHFSB_DS), event driven (DJHFSB_ED), equity long/short (DJHFSB_ELS), equity market neutral (DJHFSB_EMN), and merger arbitrage (DJHFSB_MA). DJHFSB_CA index tracks arbitrage opportunities between convertible securities and related common stocks. Managers usually trade convertible securities so as to hedge stock price, expected stock volatility, interest rate and credit rating risks. DJHFSB_DS index tracks investments in distressed securities, which exhibit promising growth prospects (despite their temporary illiquidity due to bankruptcy threat and potential reorganization process). DJHFSB_ED index takes advantage of the market’s reaction to firm-specific events (e.g., IPOs, mergers, LBOs, spin-offs, bankruptcies) and market-specific events (e.g., market news). DJHFSB_ELS index seeks for positive long exposure to market risk (which is hedged to some extent with positions on OTC derivatives). Such a strategy attempts to benefit from the potential trade-off between undervalued long positions and overvalued short positions in the U.S. equity market. DJHFSB_EMN index targets a zero exposure to market risk while combining long and short positions with similar market exposures. The equity long/short strategy attempts to identify and profit from potential market opportunities (i.e., discrepancies between fundamental values and market valuation). DJHFSB_MA index focuses on the potential benefits of the arbitrage opportunities arising between the companies, which are involved in a given merger or takeover (i.e., speculating on the prices before and after the

\footnotetext{
${ }^{4}$ Except for the Implied Volatility Index whose level we consider on a percentage basis.

${ }^{5}$ Hedge funds are generally classified with regard to their respective size and investment strategy. Therefore, hedge fund performance is envisioned in the light of the corresponding investment styles and net asset values.
} 
corporate event under consideration). ${ }^{6}$ DJHFSBIs are equal-weighted indexes, ${ }^{7}$ which are reviewed on a quarterly basis through a continuous monitoring and review process of constituent managers. The employed screening process controls for leverage and investment constraints, firm-specific risk, risk assessment (e.g., stress testing and value-at-risk), and style purity (e.g., liquidity, transparency, and return consistency) among others. ${ }^{8}$ Basically, each benchmark index (i.e., style cluster) represents approximately five to eight managers, so that 38 managers are currently represented across six investment styles (e.g., homogenous investment style clusters, and uniform investment strategies). Indeed, style purity ensures unsystematic risk reduction with few constituent managers in each DJHFSBI (Lhabitant \& Learned, 2002). Moreover, the benchmark indexes' performance reflects the respective aggregate net asset value (NAV) of each managed hedge fund within a style cluster. The hedge funds' NAVs are considered on a net-of-fees basis so that they exclude both accrued management fees and performance fees. ${ }^{9}$ Finally, DJHFSB_CA and DJHFSB_EMN indexes exhibit little exposure to equity risk. DJHFSB_CA and DJHFSB_DS indexes exhibit exposure to credit risk changes. DJHFSB_ED, DJHFSB_ELS and DJHFSB_MA indexes exhibit exposure to both equity and credit (e.g., high yield) markets.

On the other side, DJHFBPIs track a strategy's performance, which is also net of administrative and management fees, and net of operating cost. Specifically, the three DJHFBPIs are extracted from Strategy Portfolio Indexes (SPIs). SPIs are computed from DJHFSBIs while accounting for additional information such as cash accounts, liquidating manager accounts and additional platform expenses. Therefore, six SPIs are computed and combined through a specific weighting scheme to yield the DJHFBPIs under consideration. The DJHFBPIs are rebalanced so as to remain approximately equally weighted across the underlying investment strategies. For example, the DJHFBPI is equally weighted across the six investment styles above-mentioned. Namely, its respective weights are allowed to deviate from the $1 / 6$ reference proportion with a margin of only $2 \%$ (i.e., each weight may lie between $14.67 \%$ and $18.67 \%$, or equivalently $1 / 6-2 \%$ and $1 / 6+2 \%$ ). The Dow Jones Hedge Fund Balanced Portfolio index-AX (DJHFBPI_AX) tracks the performance of a liquid portfolio, which is invested in the previous style-representative SPIs except the equity long/short strategy index. Therefore, its five weights may lie between 18\% and 22\% (i.e., 1/5 \pm 2\%). The Dow Jones Hedge Fund Balanced Portfolio index-BX (DJHFBPI_BX) replicates the performance of a Euro-hedged investment in a liquid portfolio, which is allocated approximately equally across the style-representative SPIs except the equity long/short strategy index. Moreover, DJHFBPIs' composition is reviewed monthly ${ }^{10}$ whereas DJHFBPIs are rebalanced on a quarterly basis when it is necessary (i.e., when some weights happen to lie outside the allowed target(s) ensuring approximately equal-weighted portfolio allocation).

\footnotetext{
${ }^{6}$ The risk linked with the corporate event under consideration is usually diversified away in the portfolio.

7 The equal-weighting process avoids index performance skew resulting from a specific manager. Moreover, DJHFSBIs are investable indexes, which reflect then style-specific risk-return profiles. Indeed, these benchmark indexes provide investors with strategy-specific returns, which are representative of the investment styles under consideration.

${ }^{8}$ The minimum asset requirement for a benchmark fund is generally of $\$ 50$ million whereas it is of $\$ 100$ million for an equity long/short benchmark fund.

${ }^{9}$ Alfred Winslow Jones created the first hedge fund in 1949. Employing a market neutral strategy, the hedge fund applied a $20 \%$ level of incentive fees. Hedge fund managers target to hedge risk with security short selling, and to generate return based on leverage considerations. Usually, they are asked to invest a non-negligible portion of their personal wealth in the hedge fund strategy so as to bear the hedge fund's risks. As a reward, they receive incentive fees when they generate performance (i.e., hedge fund's profits). Dow Jones \& Company Inc. assumes a 2 and 20 structure, namely a $2 \%$ management fee and a $20 \%$ performance/incentive fee. The management fee is owed monthly whereas the performance fee is owed annually.

${ }^{10}$ A liquidation, which is usually due to a termination, triggers a manager's deletion from any of these indexes.
} 
Market data. The second data set is comprised of nine market indicators provided by Yahoo Finance and the U.S. federal reserve website. The first subset of five indicators refers to the U.S. equity market, namely the Dow Jones Industrial Average index (DJIA), the Dow Jones Composite Average index (DJC), the Standard \& Poor's 500 index (SP500), the Dow Jones CBOT Implied Volatility Index (VIX), and the Dow Jones Wilshire 5000 index (DWCF). Differently, the second subset of six indicators refers to the U.S. bond market, namely the one-month and three-month risk-free rates of interest, the Dow Jones CBOT Treasury index (DJCBTI), the iShares Lehman Aggregate Bond Fund NAV ${ }^{11}$ (Lehman Agg. NAV), the Lehman Bond Composite U.S. index (Lehman Comp.) and the iSharesiBoxx Investment Grade Corporate Bond Fund NAV (iBoxx IG NAV).

As regards equity market indicators, the Dow Jones Industrial Average index was first created in 1896, and is composed of 30 "blue chip" stocks. Indeed, its constituent stocks correspond to the most acknowledged and high-quality (e.g., financial strength and growth performance) companies. Moreover, the component companies may belong to any economic sector except the utilities or transportation sectors. DJIA index is a price-weighted indicator, which usually represents more than twenty percent of the U.S. stock market. In a more general way, the Dow Jones Composite Average index is composed of the 65 most solid stocks of the U.S. financial markets. Indeed, constituent stocks correspond to the 30 companies of the DJIA index, but also the 20 and 15 most outstanding companies of the transportation and utilities sectors respectively. Differently, the SP500 index was created in 1957 and is composed of 500 large-cap stocks, namely the 500 most prominent companies of the U.S. economy. SP500 index is a broad indicator of the U.S. equity market since it covers around $75 \%$ of the market (e.g., operating companies, which are representative of existing economic sectors). Indeed, the index components must have a market capitalization of at least $\$ 5$ billion and a publicly available float of at least $50 \%$ of their respective market capitalizations. Moreover, the index is computed based on float-adjusted market capitalization considerations (refer to http://www.standardandpoors.com for further details). As a larger extension, the Dow Jones Wilshire 5000 index is a broad indicator of the U.S. equity market since it covers 4,850 equity securities. The Dow Jones Wilshire 5000 index deals with the primary equity issues of U.S. companies, which provide securities with "readily available” prices (see Dow Jones \& Company, Inc. and Wilshire Associates Incorporated for further information). Moreover, its first version founded on full market capitalization considerations was first created in December 1970 whereas its floating-adjusted version was introduced later in December 1991. Hence, the DWCF index is computed based on a float-adjusted market capitalization principle ${ }^{12}$ and is reviewed monthly. From a totally different viewpoint, the CBOE volatility index was introduced in 1993 and reflects the very short-term expectations about market volatility while extracting information from SP500 option prices. Indeed, VIX index has been proved to be a relevant indicator for hedge fund returns, namely in diversification or downside risk hedge prospects (Chadwick, 2006; Dash \& Moran, 2005; McMillan, 2007). Basically, Black (2006) argues that hedge fund strategies are generally subject to significant skew and kurtosis risk, and implied volatility

\footnotetext{
${ }^{11}$ NAV stands for net asset value. We computed the return of iShares Lehman Aggregate Bond Fund's net asset value. The fund's NAV is the difference between the values of its assets and its liabilities, which is normalized by the number of outstanding shares. The assets' value stems from the closing prices of the fund's respective securities. Investors usually consider the NAV as a long-term performance indicator, which they balance with a relevant benchmark.

12 Computing equity market indexes based on the float-adjusted market capitalization principle allows for considering only shares, which are really tradable and investable. The number of shares, which are truly available to different investors in the market, is then accounted for.
} 
is correlated with significant skew and kurtosis triggers (e.g., large market moves).

As regards bond market indicators, the two short-term risk-free rates are provided by the U.S. Federal Reserve (i.e., one- and three-month U.S. Treasury bills $r_{1 M}$ and $r_{3 M}$ ). The Dow Jones CBOT Treasury index was created in April 2004 in order to replicate the performance of the U.S. Treasury Bond Market. It is representative of the default-free U.S. fixed income market and illustrates the market reaction to economic evolution as well as market expectations. The DJCBTI index is composed of three futures contracts (i.e., the CBOT five-year Treasury note, the CBOT ten-year Treasury note and the CBOT Treasury bond futures). Specifically, it is weighted by Macaulay modified duration and updated on a quarterly basis. We therefore consider two different risk-free rate proxies. Concerning the remaining data, iShares denomination applies to Barclays Global Investors' exchange-traded funds. ${ }^{13}$ Specifically, an iShare fund targets to replicate a benchmark index from the stock market or the bond market. Namely, the iShares Lehman Aggregate Bond Fund started in September 22, 2003 and replicates the performance ${ }^{14}$ (e.g., price and yield profiles before fees and expenses) of the U.S. investment-grade bond market as represented by the Lehman Brothers U.S. Aggregate Bond Index. The Lehman Brothers U.S. Aggregate Bond Index is a monthly rebalanced index, which is weighted by market capitalization. It was created in January 1986, and is composed of approximately 9,200 securities at the end of 2007. Basically, this index is composed of the Lehman Brothers Government/Corporate Bond, Mortgage-Backed Securities (MBS), Asset-Backed Securities (ABS) and Commercial Mortgage-Backed Securities (CMBS) indexes, and handles investment-grade securities with both a time to maturity of one year or more and an outstanding par value of \$ 100 million or above. ${ }^{15}$ Specifically, Lehman Brothers Government/Corporate Bond index refers to treasury, government and corporate bonds (i.e., government and corporate debt). Lehman Brothers MBS index and Lehman Brothers ABS index refer respectively to securitized mortgage baskets ${ }^{16}$ with fixed rate on one side, and to credit card, auto and home equity loans on the other side. Lehman Brothers CMBS index accounts for the investment-grade, high yield, interest-only and "commercial conduct whole loan" segments. As an extension, Lehman Brothers provide investors with customized indexes such as Lehman Bond Composite U.S. index. Lehman Comp. index is designed to match specific cash flow objectives. For this purpose, this index is a combination of existing Lehman Brothers' indexes. Basically, the Lehman Brothers U.S. Aggregate index represents $50 \%$ of Lehman Comp. index whereas the remaining 50\% consists of the Lehman Brothers Intermediate Government/Credit, MBS and ABS indexes. Finally, the iShares Investment Grade Corporate Bond Fund was created in July 22, 2002. The iBoxx IG NAV tracks the performance profile (i.e., price and yield levels before fees and expenses) of the investment grade corporate market as represented by the iBoxx Liquid Investment Grade index. ${ }^{17}$ The iBoxx Liquid Investment Grade index is composed of 100 highly liquid,

\footnotetext{
${ }^{13}$ An exchange-traded fund (ETF) is a basket of assets (e.g., stocks, bonds, futures), which is traded on stock exchanges. ETFs are traded since 1993 in the United States. This investment vehicle allows for tracking the net asset value of the fund's underlying assets (e.g., redemption and creation units features).

${ }^{14}$ While setting up an index tracking strategy.

15 Moreover, constituent securities need to be U.S. dollar-denominated, fixed-rate, non-convertible and taxable assets.

16 Mortgage pass-through securities such as Ginnie Mae (GNMA), Fannie Mae (FNMA) and Freddie Mac (FHLMC).

17 Formerly, a group of dealers composed of Deutsche Bank, ABN Amro and Citigroup among others, created iBoxx indexes. The iBoxx index series offer various exposures to the credit risk (i.e., specific asset class) all over the world. Introduced in 1999 as the GS \$ InvesTop index, the iBoxx Liquid Investment grade index was initially created by Goldman Sachs Group Inc. and encompassed 30 components. On July 1 2002, it was then enlarged to 100 components so as to offer a better representativeness of the financial market under consideration.
} 
investment grade and fixed income U.S. dollar-denominated corporate bonds (i.e., corporate debt issues). It is representative of the broad corporate bond market under a strong liquidity constraint. Indeed, constituent bonds must have a minimum residual time to maturity of 3.5 years, an outstanding value of at least $\$ 500$ million; fulfill Lehman Brothers' liquidity assessment process. Moreover, iBoxx Liquid Investment Grade index is a price-weighted index with equal price weights, and is rebalanced on a monthly basis. ${ }^{18}$

\section{Key Features}

We introduce here some useful and specific descriptive statistics, which give a good representation/characterization of the data under consideration. Table 1 and Table 2 display related mean, median, volatility (i.e., standard deviation) values as well as corresponding skewness and kurtosis moments. Skewness and kurtosis are important distribution indicators insofar as they allow for describing well-known risk asymmetries (e.g., risk proportion with which a time series tend to deviate from its average level, and the heaviness of such a risk as described by the number of observations far enough from the mean value, be it from below or from above sides). As a complement, Figure 1 helps assessing the impact of such higher moments with comparison to median hedge fund returns.

Table 1

Descriptive Statistics of Hedge Fund Indexes

\begin{tabular}{|c|c|c|c|c|c|c|}
\hline DJHF index & Mean & Median & Std. Dev. & Skewness & Excess Kurstosis & $\begin{array}{l}\text { Min. (Max.) } \\
\text { [Range] }\end{array}$ \\
\hline SB_CA & 0.0096 & 0.0222 & 0.2066 & -0.6946 & 3.2724 & $\begin{array}{l}-1.1809 \\
(0.7834) \\
{[1.9643]}\end{array}$ \\
\hline SB_DS & 0.0209 & 0.0346 & 0.1797 & -0.1931 & 2.2998 & $\begin{array}{l}-0.6438 \\
(1.0129) \\
{[1.6567]}\end{array}$ \\
\hline SB_ED & 0.0295 & 0.0516 & 0.2809 & -0.4795 & 1.3416 & $\begin{array}{l}-1.1331 \\
(0.9818) \\
{[2.1148]}\end{array}$ \\
\hline SB_EMN & 0.0119 & 0.0000 & 0.1928 & -0.5377 & 33.2950 & $\begin{array}{l}-1.8233 \\
(1.7537) \\
{[3.5770]}\end{array}$ \\
\hline SB_MA & 0.0336 & 0.0414 & 0.2384 & -0.5460 & 3.9356 & $\begin{array}{l}-1.3488 \\
(0.8985) \\
{[2.2473]}\end{array}$ \\
\hline ELS & 0.0325 & 0.0687 & 0.5158 & -0.5331 & 2.0077 & $\begin{array}{l}-2.3231 \\
(2.4459) \\
{[4.7689]}\end{array}$ \\
\hline BPI & 0.0207 & 0.0434 & 0.1823 & -0.7326 & 2.4654 & $\begin{array}{l}-0.8461 \\
(0.7277) \\
{[1.5739]}\end{array}$ \\
\hline BPI_AX & 0.0194 & 0.0337 & 0.1361 & -0.7492 & 2.8764 & $\begin{array}{l}-0.6802 \\
(0.5187) \\
{[1.1989]}\end{array}$ \\
\hline BPI_BX & 0.0118 & 0.0239 & 0.1443 & -0.7114 & 2.9836 & $\begin{array}{l}-0.7445 \\
(0.6118) \\
{[1.3563]}\end{array}$ \\
\hline
\end{tabular}

${ }^{18}$ Refer to Markit Group Limited at http://www.markit.com for further details. 
As regards Table 1, hedge fund indexes exhibit a negative skewness and an obviously positive excess kurtosis as reported in the previous literature (Black, 2006; Eling, 2006; Eling \& Schuhmacher, 2006; Taleb, 2007). We are therefore far from the ideal Gaussian profile (Eling, 2006; Taleb, 2007). According to Black (2006), skewness and kurtosis reflect the event and liquidity risks ${ }^{19}$ taken by hedge funds whereas Brooks and Kat (2002) point out the uninteresting high Sharpe ratios in the presence of negative skewness and positive excess kurtosis. Moreover, DJHFBPI_AX returns exhibit the lowest standard deviation and skewness statistics. Furthermore, the average hedge fund returns generally lie below related median hedge fund returns except for DJHFSB_EMN returns. If a style-specific hedge fund performance results from the trade-off between mean or median returns on one side, and both skewness and excess kurtosis on the other side, then the issue is not clear or even obvious. It seems hard to draw conclusions based on the only observation of low and high order statistics.

Table 2

Descriptive Statistics of Market Data

\begin{tabular}{|c|c|c|c|c|c|c|}
\hline Market data & Mean & Median & Std. Dev. & Skewness & Excess kurstosis & $\begin{array}{l}\text { Min. (Max.) } \\
\text { [Range] }\end{array}$ \\
\hline$r_{1 M}$ & 0.0111 & 0.0116 & 0.0027 & -0.4264 & -1.1515 & $\begin{array}{c}0.0046 \\
(0.0146) \\
{[0.0101]}\end{array}$ \\
\hline$r_{3 M}$ & 0.0114 & 0.0122 & 0.0026 & -0.5028 & -1.1460 & $\begin{array}{c}0.0054 \\
(0.0144) \\
{[0.0090]}\end{array}$ \\
\hline DJCBTI & 0.0071 & 0.0000 & 0.2820 & 0.0390 & 1.0341 & $\begin{array}{l}-1.2576 \\
(1.0304) \\
{[2.2879]}\end{array}$ \\
\hline DJIA & 0.0205 & 0.0509 & 0.7767 & -0.4260 & 1.6925 & $\begin{array}{l}-3.2933 \\
(2.5544) \\
{[5.8477]}\end{array}$ \\
\hline DJC & 0.0312 & 0.0846 & 0.8629 & -0.2554 & 1.3819 & $\begin{array}{l}-3.2509 \\
(4.0279) \\
{[7.2788]}\end{array}$ \\
\hline SP500 & 0.0173 & 0.0788 & 0.8190 & -0.4101 & 2.0053 & $\begin{array}{l}-3.4725 \\
(2.9208) \\
{[6.3933]}\end{array}$ \\
\hline VIX & 14.9075 & 13.1400 & 4.7092 & 1.4971 & 1.3243 & $\begin{array}{c}9.8900 \\
(31.0900) \\
{[21.2000]}\end{array}$ \\
\hline DWCF & 0.0199 & 0.0819 & 0.8297 & -0.3775 & 1.6474 & $\begin{array}{l}-3.4099 \\
(2.9208) \\
{[6.3307]}\end{array}$ \\
\hline $\begin{array}{l}\text { Lehman } \\
\text { Agg. } \\
\text { NAV }\end{array}$ & -0.0007 & 0.0099 & 0.2177 & -0.2338 & 1.0044 & $\begin{array}{l}-0.9093 \\
(0.7614) \\
{[1.6707]}\end{array}$ \\
\hline $\begin{array}{l}\text { Lehman } \\
\text { Comp. }\end{array}$ & 0.0608 & 0.0113 & 3.0876 & 8.1319 & 223.4001 & $\begin{array}{l}-33.7513 \\
(51.1168) \\
{[84.8681]}\end{array}$ \\
\hline $\begin{array}{l}\text { iBoxx } \\
\text { IG } \\
\text { NAV }\end{array}$ & -0.0077 & 0.0094 & 0.2589 & -0.2336 & 0.6375 & $\begin{array}{l}-0.9995 \\
(0.7656) \\
{[1.7650]}\end{array}$ \\
\hline
\end{tabular}

${ }^{19}$ Moreover, these risks are correlated with equity volatility. 
As regards Table 2, DJCBTI, VIX and Lehman Comp. indicators exhibit a positive skewness whereas the other market data exhibit a negative skewness (i.e., more values lie below the time series' historical average as compared to the number of values lying above the historical average). Moreover, all the market data exhibit a positive excess kurtosis except the risk-free rate of interest (i.e., fatter tails than the Gaussian distribution). Furthermore, market data averages are generally lower than related median values except for DJCBTI, VIX and Lehman Comp. indicators (due to their related right skew). Finally, the risk-free rate of interest exhibits a low standard deviation and evolves therefore around its historical average.

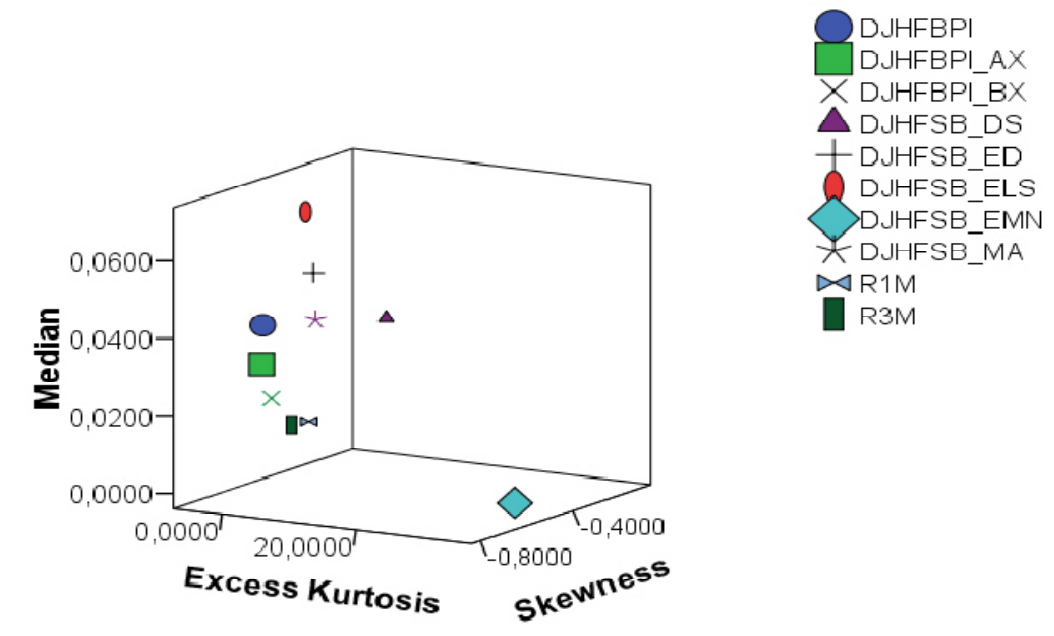

Figure 1. Hedge fund indexes and risk-free rates statistics.

As firstly exhibited in Figure 1, the two benchmark risk-free rates are very similar in terms of higher order moments and median values. Second, the hedge fund benchmark indexes can be split into four groups in terms of skewness and kurtosis statistics. The first cluster consists of DJHFBPI, DJHFBPI_AX and DJHFBPI_BX indexes whereas the second cluster corresponds to DJHFSB_MA, DJHFSB_ED and DJHFSB_ELS indexes. Finally, DJHFSB_DS and DJHFSB_EMN indexes are two distinct unit clusters by themselves. Moreover, the non-Gaussian behavior of previous data is clear since they do not lie on the far right vertical axis. And, the heterogeneous nature of hedge fund data as represented by the hedge fund indexes under consideration is obvious (i.e., stylized fact due to the optional nature underlying certain hedge fund strategies and styles such as volatility short-selling for example). Indeed, merger arbitrage, certain fixed income arbitrage, and statistical arbitrage (i.e., pair trading) strategies among others belong to the class of short-volatility investing strategies. ${ }^{20}$ Moreover, the selected reporting frequencies and trading strategies (i.e., degree of aggressiveness) impact reported returns and related volatility (i.e., hedge fund performance). ${ }^{21}$

\footnotetext{
${ }^{20}$ Such volatility strategies contribute to the risk asymmetries between hedge fund styles and related performance. For example, the main risk sources describing mortgage-backed securities strategies are the underlying class performance, the corresponding leverage, and the exposure structure of managers' fixed-income options (e.g., volatility short sales). Differently, convertible arbitrage strategies are essentially exposed to equity and corporate bond markets' reversals, and volatility increases in the fixed-income market (Weisman \& Abernathy, 2000).

${ }^{21}$ See Veinstein and Abdulali (2002). For example, Weisman and Abernathy (2000) draw attention to the relationship between options' shortsale and volatility. They explain that fixed income options' shortsales attempt to replicate managers' low volatility. They also report a high and significant serial correlation in monthly returns. Considering these correlation results of Weisman and Abernathy (2000), we understand where the non-Gaussian feature of hedge fund returns comes from.
} 


\section{Proposing a Correction}

We propose a correction for two classical performance measures, which were proved to be unadapted to assess hedge funds performance among others. The lack of coherency is due to the violation of the well-known Gaussian behavioral assumptions for market data (i.e., security returns). Indeed, hedge fund returns are highly asymmetric and exhibit significant skewness (Black, 2006; Eling, 2006; Getmansky, Lo, \& Makarov, 2004; Taleb, 2007).

\section{Simple Considerations}

We underline here the impact of skewness and kurtosis on two classical performance measures, namely Sharpe and Treynor ratios. These two performance indexes are founded on the Gaussian asset return assumption. Under symmetric distributions such as the Gaussian law, mean and variance moments are sufficient to describe the financial universe. Indeed, the efficient mean-variance setting à la Markowitz describes conveniently the financial market in terms of risk-return trade-off. This is due to the fact that the standard deviation metric is representative of the risk of deviating from the mean value (i.e., upside and downside risks are symmetric). However, under an asymmetric distribution setting the previous comments no more holds, and we need to account for the asymmetric downside (i.e., left tail) and upside (i.e., right tail) risk profiles (e.g., fat-tailed hedge fund returns documented by Eling (2006) among others). In such a case, mean and variance moments are no more sufficient to describe assets' risk levels so that returns' volatility (i.e., standard deviation) misestimates hedge fund risks (Kat, 2005; Khanniche, 2008; Liang \& Park, 2007). Therefore, the significance of the higher moments above-mentioned biases the ranking inferred from the previous Gaussian-based performance measures. Namely, the mean-variance framework underestimates the downside risk as represented by the risk related to negative outcomes (Agarwal \& Naik, 2004). And, the left-tail risk as represented by the skewness statistic may grow as the portfolio's (i.e., the fund's) diversification level increases (Harvey, Liechty, \& Müller, 2004; Liang \& Park, 2007). By the way, Goldman (2003) and Hull (2006, 2007) show that probability-based measures such as Value-at-Risk (VaR) are flawed, and advocate the use of downside volatility risk measures (e.g., expected shortfall is a better risk measure than VaR due to its sub-additivity property). Indeed, Liang and Park (2007) show expected shortfall and tail risk measures to capture strongly the left-tail risk describing the cross-sectional discrepancies in hedge fund returns. Moreover, in terms of risk measure effectiveness, expected shortfall is better than $\mathrm{VaR}$ for measuring downside risk whereas the Cornish-Fisher setting is better than both expected shortfall and tail risk measures (after controlling for hedge funds' style, liquidity, age, and size features). Consequently, higher order moments have to be considered while assessing hedge fund risk and performance, and in order to account for return heterogeneity as well as style heterogeneity ${ }^{22}$ (Ackermann, McEnally, \& Ravenscrat, 1999; Boyson, 2003; Mc Fall Lamm, 2003; Moix \& Schmidhuber, 2001).

Assuming Gaussian security and portfolio returns, Sharpe ratio $(S)$ and Treynor ratio $(T)$ represent the security risk premium adjusted by the security return's volatility (i.e., the security return's global risk) and the security's systematic risk $^{23}$ (i.e., the security's beta as defined by Sharpe's CAPM) respectively (Sharpe, 1966, 1994; Treynor, 1965). Put in the other way, Sharpe and Treynor indexes are simply the excess returns per unit of global risk and per unit of systematic risk respectively. They write:

\footnotetext{
22 Namely, heterogeneity results from the discrepancies in fund characteristics.

23 The computation of the corresponding beta relies on the mean-variance efficiency of the selected market index.
} 


$$
\begin{aligned}
& S=\text { Sharpe }=\frac{\mu-\overline{r_{f}}}{\sigma} \\
& T=\text { Treynor }=\frac{\mu-\overline{r_{f}}}{\beta}
\end{aligned}
$$

where $\mu$ and $\overline{r_{f}}$ are the arithmetic means of the security return and the risk-free rate over the studied time horizon; $\sigma$ is the security return's standard deviation. And finally, $\beta=\operatorname{Cov}(P, M) / \sigma_{M}^{2}=\operatorname{Cov}\left(P-\overline{r_{f}}, M-\overline{r_{f}}\right) / \sigma_{M}^{2}$ is the security return's beta so that $P$ and $M$ are the respective returns of the security and the market portfolio under consideration; $\sigma_{M}^{2}$ is the variance of the market portfolio's return over the studied time horizon. ${ }^{24}$

Unfortunately, these two reference measures exhibit well-known biases (Benefield, Anderson, \& Zumpano, 2007; Boyson, 2003; Hodges, 1998; Kat \& Miffre, ${ }^{25}$ 2003; Klemkosky, 1973; Spurgin ${ }^{26}$ 2001; Veinstein \& Abdulali, ${ }^{27}$ 2002). First, Sharpe index penalizes any security presenting unusually high returns (Miller \& Gehr, 1978). Second, the quality of Sharpe ratio as well as the resulting fund ranking depends on the prevailing market trend (Scholz \& Wilkens, 2005). ${ }^{28}$ As an extension, Carretta and Mattarocci (2009) show that classic risk adjusted performance measures fail to distinguish the best hedge fund performers, and that related fund rankings are non-persistent over time. ${ }^{29}$ Moreover, Sharpe ratio doesn't account for how much a return series deviates from its historical average value from below or from above. The only deviation measure is the standard deviation, or equivalently volatility (i.e., no range considerations). The last remark also applies to Treynor ratio through the covariance and variance measures employed in beta's computation. Finally, the choice of the market index may be critiqued (Jobson \& Korkie, 1981; Roll, 1978).

Taking into account the capability and magnitude of return time series to deviate from their historical means, we can rewrite Sharpe and Treynor indexes as follows: ${ }^{30}$

$$
\begin{gathered}
S=w_{-} \times \frac{\mu-\overline{r_{f}}}{\sigma}+w_{+} \times \frac{\mu-\overline{r_{f}}}{\sigma} \\
T=\frac{\mu-\overline{r_{f}}}{\beta} \text { with } \beta=\frac{w_{M_{-}} \sigma_{P M, 5}+w_{M_{+}} \sigma_{P M, 6}}{w_{M-} \sigma_{M-}^{2}+w_{M+} \sigma_{M+}^{2}}
\end{gathered}
$$

where $w_{-}=n_{-} / n$ and $w_{+}=n_{+} / n$ are weights; $w_{M_{-}}=n_{M_{-}} / n$ and $w_{M_{+}}=n_{M_{+}} / n$ are also weights; while $\sigma_{P M, 5}=\sum_{t=1, M_{t} \leq \mu_{M}}^{n}\left(P_{t}-\mu\right)\left(M_{t}-\mu_{M}\right) / n_{M-}, \quad \sigma_{P M, 6}=\sum_{t=1, M_{\imath}>\mu_{M}}^{n}\left(P_{t}-\mu\right)\left(M_{t}-\mu_{M}\right) / n_{M+}, \quad \sigma_{M-}^{2}=\sum_{t=1, M_{t} \leq \mu_{M}}^{n}\left(M_{t}-\mu_{M}\right)^{2} / n_{M-}$

\footnotetext{
${ }^{24}$ The observed values of $\sigma_{M}^{2}$ are almost similar when we consider either the market benchmark return or its corresponding excess return (relative to the risk free rate).

25 Those authors show that static risk adjusted performance measures are inappropriate under time series asymmetry settings. Moreover, Sharpe ratio tends to overestimate hedge fund performance (i.e., better excess return and/or lower risk level as measured by returns' standard deviation).

26 This author emphasizes the performance overestimation generated with Sharpe ratio.

27 The authors underline the inappropriateness of Sharpe ratio to assess funds focusing on illiquid assets (e.g., mortgage-backed securities, high-yield and convertible bonds). They propose to extend Sharpe ratio in order to account for liquidity risk. For this purpose, they implement a new risk adjusted performance measure under a utility-based framework (i.e., to account for investor preferences).

${ }^{28}$ Those authors show that Sharpe ratio is biased by the market climate.

29 The authors advocate the use of more appropriate risk measures in volatile market conditions. However, the trade-off between the complexity and the usefulness of possible risk adjusted performance measures has to be considered.

30 The proofs are available upon request from the author.
} 
and $\sigma_{M+}^{2}=\sum_{t=1, M_{>}>\mu_{M}}^{n}\left(M_{t}-\mu_{M}\right)^{2} / n_{M+}$ are deviation risk measures. The number of observed cases when security or portfolio return $P$ and market return $M$ lie below (or strictly above) their historical mean values are labeled $n_{-}$ and $n_{M_{-}}$( $n_{+}$and $n_{M_{+}}$) respectively. The significance of this writing is such that $\sigma_{M_{-}}$is the average downside deviation and $\sigma_{M+}$ is the average upside deviation from the market return's mean. The same definitions apply respectively to the average downside and upside deviations $\sigma_{-}$and $\sigma_{+}$of the portfolio's return (see Figure 2).

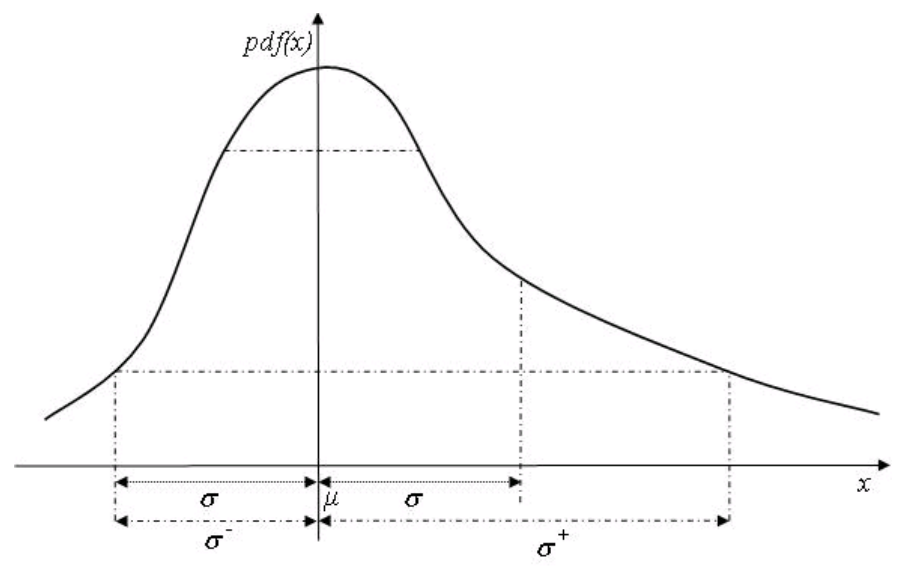

Figure 2. Asymmetric probability density function.

Therefore, the potential biases appear clearly intuitive insofar as both classic risk-adjusted performance measures do not disentangle the existence and magnitude of potential right and left skews in return time series. Indeed, Sharpe index and the beta measure employed in Treynor ratio rely on non-homogeneous skew considerations. Consider Sharpe ratio for example, and suppose a positive outlier ${ }^{31}$ return exists in a hedge fund return time series. Then, both the historical mean and the standard deviation of returns increase so that the resulting excess return increases as well. The impact on the Sharpe ratio depends on the magnitude of such outlier return, and results from the trade-off between the subsequent joint increases in the excess return and the corresponding standard deviation. In the reverse case of a negative outlier return, the impact on the return time series is more obvious since both the historical mean decreases and the related standard deviation increases. As a consequence, the excess return decreases and the combined effect on the mean and standard deviation statistics is so that the obtained Sharpe ratio is lowered (i.e., downward bias; see Appendix A for further explanations). Such effects are all the more important when you face an accumulation of outlier returns as described by skewness and kurtosis statistics. ${ }^{32}$ To summarize, the skewness and kurtosis patterns of returns generate a bias in both risk level assessment (as measured by standard deviation) and performance ranking (as implied by Sharpe and Treynor index levels). We propose then to render the two previous classic risk-adjusted performance measures more homogeneous in terms of skew risk, and to offset the related skew-based biases.

31 An outlier return is an observed return whose value is, to some extent, far enough from the historical mean of the corresponding time series. A positive outlier lies far above the mean whereas a negative outlier lies far below the mean (i.e., magnitude of distribution around the mean value).

${ }^{32}$ The observed bias in performance measures reflects the cost of outlier returns. Specifically, outliers impact both the mean and standard deviation of the return time series so that these indicators are no more sufficient risk descriptors. Moreover, outlier returns often generate deviations from the Gaussian standard representation so that skewness and kurtosis indicators need to be considered for risk prospects. Hence, the cost of outliers is materialized by a impairment of classic performance measures. 


\section{A Natural Correction}

We introduce here a correction aimed at rebalancing the presence of skewness and kurtosis while assessing the performance of a hedge fund for example. The basic idea is simple insofar as we just account for the existing skewness, namely the ability of a return time series to deviate frequently from its average value in an asymmetric manner (i.e., the asymmetry between the proportion of observed returns lying above the time series' mean and the proportion of observed returns lying below the mean value in some statistical sense). ${ }^{33}$ Namely, the asymmetry between upside deviations and downside deviations from the mean value is closely linked with skewness. And, we also account for the kurtosis effect, namely the significance and the magnitude of the asymmetry in the distribution of a return time series around its average value (i.e., fat tail features and asymmetric tail patterns). ${ }^{34}$ Namely, the respective magnitudes of upside and downside deviations are closely linked with kurtosis (i.e., probability of observing extreme moves). Taking into account such asymmetries yields homogeneous performance measure formulas while weighting the cases were a time series lies above or below its average value by the related frequency of observed cases.

We propose therefore the following modified version $S^{*}$ of Sharpe ratio:

$$
\begin{aligned}
S^{*} & =w_{-} \times \frac{\mu_{-}-\overline{r_{f}}}{\sigma_{-}}+w_{+} \times \frac{\mu_{+}-\overline{r_{f}}}{\sigma_{+}} \\
& =w_{-} \times S_{-}+w_{+} \times S_{+}
\end{aligned}
$$

where $S^{*}$ is a skew-specific adjusted risk premium (SSARP) so that $S_{-}$and $S_{+}$are left-skew specific (LSSARP) and right-skew specific (RSSARP) adjusted risk measures respectively (i.e., downside and upside Sharpe ratios). It corresponds to the weighted average of the left-skewed adjusted risk premium $\left(\mu_{-}-\overline{r_{f}}\right) / \sigma_{-}$and the right-skewed adjusted risk premium $\left(\mu_{+}-\overline{r_{f}}\right) / \sigma_{+}$, which is coherent with the bias underlined by Scholz and Wilkens (2005). In the same line, we also consider the slightly different version $S^{* *}$ as follows:

$$
S^{* *}=w_{-} \times \frac{\mu-\overline{r_{f}}}{\sigma_{-}}+w_{+} \times \frac{\mu-\overline{r_{f}}}{\sigma_{+}}=w_{-} \times S_{-}^{\prime}+w_{+} \times S_{+}^{\prime}
$$

so that we account clearly for the deviations of returns from their historical means. It corresponds to the weighted average of the left-skewed adjusted risk premium $S_{-}^{\prime}=\left(\mu-\overline{r_{f}}\right) / \sigma_{-}$the right-skewed adjusted risk premium $S_{+}^{\prime}=\left(\mu-\bar{r}_{f}\right) / \sigma_{+}$, except that the risk premia are relative to the original returns' mean. In this second modified version, we encompass the original Sharpe ratio when the portfolio's return time series is symmetric (e.g., Gaussian distribution for returns).

We also propose two modified versions of the Treynor ratio. The first new version $T^{*}$ relies on a modified version $\beta^{*}$ of Sharpe's beta depending on the downside or upside market risk patterns.

$$
T^{*}=\frac{\mu-\overline{r_{f}}}{\beta^{*}}
$$

where

$$
\beta^{*}=w_{M-} \frac{\sigma_{P M, 5}}{\sigma_{M-}^{2}}+w_{M+} \frac{\sigma_{P M, 6}}{\sigma_{M+}^{2}}
$$

Indeed, beta is weighted and defined with regard to the right and left skews of the market return. And, it

\footnotetext{
${ }^{33}$ Loss and gain probabilities are asymmetric.

34 There exist magnitude discrepancies in the probabilities of facing extreme negative and positive events.
} 
considers the related partial covariances between the hedge fund index return and the market return. We obtain the original Treynor ratio when the market return's series is symmetric. In the same line, the second new version $T^{* *}$ is an improved performance risk-adjusted measure derived from Treynor principle. It is an adapted Treynor ratio, which relies on an upside $\beta_{+}$and a downside $\beta_{-}$Sharpe's beta. Specifically, $T^{* *}$ is the weighted average of an upside and a downside market-focused Treynor ratio:

$$
T^{* *}=w_{M-} \frac{\mu-\bar{r}_{f}}{\beta_{-}}+w_{M+} \frac{\mu-\bar{r}_{f}}{\beta_{+}}
$$

where $\quad \beta_{-}=\sigma_{P M, 5} / \sigma_{M-}^{2}=\operatorname{Cov}(P, M) \times \mathbf{1}\left\{M_{t} \leq \mu_{M}\right\} / \sigma_{M-}^{2} \quad$ and $\quad \beta_{+}=\sigma_{P M, 6} / \sigma_{M+}^{2}=\operatorname{Cov}(P, M) \times \mathbf{1}\left\{M_{t}>\mu_{M}\right\} / \sigma_{M+}^{2} \quad$ are respectively the downside and upside hedge fund index beta relative to the market benchmark under consideration. ${ }^{35}$ The dummy function $\mathbf{1}\left\{M_{t} \leq \mu_{M}\right\}$, for example, is unity when the observed returns $\left(M_{t}\right)$ of the market portfolio are below their corresponding historical mean.

As a complementary investigation, we also propose a specific Treynor ratio $T^{\prime}$ when the market benchmark under consideration is SP500 index. In particular, we set $T^{\prime}=\left(\mu-\bar{r}_{f}\right) / \beta^{\prime}$ where $\beta^{\prime}=\operatorname{Cov}(P / V I X, S P 500 / V I X)$ and VIX represents the implied volatility index. Though realized market volatility is usually lower than implied volatility (Whaley, 2002; Feldman \& Roy, 2005); implied market volatility is a good indicator of market uncertainty.

\section{Numerical Application}

We apply here the correction to the previous classical performance measures so as to reduce the observed bias induced by skewness and kurtosis concerns. We also compare the obtained performance assessment and rankings with the ones inferred from classic performance measures.

\section{Sharpe Index}

We compute Sharpe ratios while considering two different risk-free rate benchmarks $\overline{r_{f}}$ (i.e., $r_{3 M}$ and DJCBTI index ${ }^{36}$ representative of the U.S.. Treasury bond market and while replacing the market benchmark $M$ with other appropriate stock market indexes. As a first step, we display corresponding downside and upside Sharpe ratios in Table 3. Then, we display in Table 4 the results we obtain when considering the classic and corrected Sharpe index as represented by equations (1), (5) and (6). Results are computed while considering two different risk-free rate benchmarks, namely the three-month Treasury bill rate and the DJCBTI return. Recall that daily returns are considered on a percentage basis.

Previous results yield an interesting ranking of our hedge fund benchmark indexes and portfolios. First, we classify computed Sharpe ratios as increasing functions of the obtained values (see Table 5).

Second, the results displayed in the previous tables give an interesting characterization of the hedge fund industry and the corresponding risk/return profiles. As regards downside and upside Sharpe ratios, the ratios corresponding to DJCBTI benchmark are higher in value than the ones corresponding to the three-month risk-free rate benchmark. Whatever the risk-free rate benchmark under consideration and under $S^{*}$ setting, DJHFSB_EMN index exhibits the highest values for downside Sharpe ratios and the smallest values for upside Sharpe ratios. Whatever the risk-free rate benchmark under consideration and under $S^{* *}$ setting, DJHFSB_CA

\footnotetext{
35 The beta parameters are focused on the downside and upside market risks respectively as compared to the observed historical market's mean.

${ }^{36}$ Since the one- and three-month risk-free interest rates behave in a similar way and results are very close whatever the short-term risk-free rate under consideration, we display only the results obtained with the three-month risk-free rate of interest.
} 
index and DJHFSB_MA exhibit respectively the lowest and highest values for both downside and upside Sharpe ratios. Moreover, estimated downside and upside Sharpe ratios are very close in terms of absolute value for DJHFSB_EMN index case. Such feature illustrates the risk/return trade-off embedded in the hedge fund equity market neutral strategy. Namely, we have approximately the same relative loss and gain profiles (around the average return level) in terms of risk and return characteristics (i.e., approximate symmetry in downside and upside risks). On the reverse, obtained downside and upside Sharpe ratios exhibit clearly different absolute levels for all other hedge fund indexes. We face a clear asymmetry in the downside and upside risks of deviation from the average return, namely asymmetric downside and upside risks. As regards classic Sharpe ratio, we obtain the same ranking for 77.7778 percent of Dow Jones hedge fund indexes whatever the risk-free rate benchmark under consideration. As regards the first $S^{*}$ and second $S^{* *}$ new Sharpe ratios, the corresponding percentages fall to 44.4444 percent and 55.5556 percent respectively. Moreover, the obtained ranking is totally different when we switch from the classic to the new Sharpe ratio. Accounting for time series asymmetry induces then a structural change in the ranking.

Table 3

Downside and Upside Sharpe Ratios

\begin{tabular}{|c|c|c|c|c|c|c|c|c|}
\hline \multirow{2}{*}{$\begin{array}{l}\text { DJHF } \\
\text { index }\end{array}$} & \multicolumn{2}{|c|}{$S_{-}$} & \multicolumn{2}{|c|}{$S_{+}$} & \multicolumn{2}{|c|}{$S_{-}^{\prime}$} & \multicolumn{2}{|c|}{$S_{+}^{\prime}$} \\
\hline & $r_{3 M}$ & DJCBTI & $r_{3 M}$ & DJCBTI & $r_{3 M}$ & DJCBTI & $r_{3 M}$ & DJCBTI \\
\hline SB_CA & -0.7053 & -0.6864 & 0.7512 & 0.7740 & -0.0081 & 0.0108 & $\begin{array}{l}-0.0098 \\
\end{array}$ & 0.0130 \\
\hline SB_DS & -0.6944 & -0.6728 & 0.7885 & 0.8144 & 0.0484 & 0.0701 & 0.0580 & 0.0840 \\
\hline SB_ED & -0.6719 & -0.6582 & 0.8381 & 0.8550 & 0.0581 & 0.0718 & 0.0717 & 0.0886 \\
\hline SB_EMN & -0.5805 & -0.5576 & 0.6315 & 0.6529 & 0.0027 & 0.0255 & 0.0025 & 0.0239 \\
\hline SB_MA & -0.5940 & -0.5770 & 0.8285 & 0.8474 & 0.0886 & 0.1056 & 0.0987 & 0.1176 \\
\hline SB_ELS & -0.6841 & -0.6768 & 0.8063 & 0.8157 & 0.0364 & 0.0437 & 0.0465 & 0.0559 \\
\hline BPI & -0.6836 & -0.6637 & 0.8214 & 0.8491 & 0.0432 & 0.0631 & 0.0602 & 0.0879 \\
\hline BPI_AX & -0.6770 & -0.6500 & 0.8276 & 0.8642 & 0.0504 & 0.0774 & 0.0685 & 0.1052 \\
\hline BPI_BX & -0.7003 & -0.6742 & 0.7590 & 0.7928 & 0.0022 & 0.0283 & 0.0029 & 0.0367 \\
\hline
\end{tabular}

Table 4

Classic and New Sharpe Ratios

\begin{tabular}{|c|c|c|c|c|c|c|}
\hline \multirow{2}{*}{$\begin{array}{l}\text { DJHF } \\
\text { index }\end{array}$} & \multicolumn{2}{|c|}{$S$} & \multicolumn{2}{|c|}{$S^{*}$} & \multicolumn{2}{|c|}{$S^{* *}$} \\
\hline & $r_{3 M}$ & DJCBTI & $r_{3 M}$ & DJCBTI & $r_{3 M}$ & DJCBTI \\
\hline SB_CA & -0.0089 & 0.0070 & 0.0580 & 0.0789 & -0.8987 & 1.1923 \\
\hline SB_DS & 0.0532 & 0.0383 & 0.1202 & 0.1443 & 5.3711 & 7.7744 \\
\hline SB_ED & 0.0644 & 0.0510 & 0.1442 & 0.1597 & 6.5432 & 8.0872 \\
\hline SB_EMN & 0.0026 & 0.0138 & -0.0175 & 0.0047 & 0.2599 & 2.4757 \\
\hline SB_MA & 0.0934 & 0.0671 & 0.1317 & 0.1496 & 9.3754 & 11.1727 \\
\hline SB_ELS & 0.0410 & 0.0396 & 0.1328 & 0.1413 & 4.1928 & 5.0386 \\
\hline BPI & 0.0509 & 0.0365 & 0.1755 & 0.1999 & 5.2922 & 7.7282 \\
\hline BPI_AX & 0.0587 & 0.0363 & 0.1743 & 0.2068 & 6.0658 & 9.3119 \\
\hline BPI_BX & 0.0025 & 0.0135 & 0.0977 & 0.1280 & 0.2581 & 3.2892 \\
\hline
\end{tabular}




\section{Treynor Index}

We provide the estimates for the new Treynor ratio after accounting for skewness and kurtosis patterns in asset returns. We consider successively the available risk-free rate benchmarks and their replacement with other interest rate benchmarks representative of the U.S. bond market. We also consider bond and market benchmarks to check for the behavior of Treynor ratios. Classic and modified Treynor indexes are displayed in Tables 6-11 whereas a set of classic and modified betas are proposed in Tables 12-15 for a set of possible market benchmarks. ${ }^{37}$ As a rough guide, the upside and downside betas relative to $T^{* *}$ risk-adjusted performance measure are displayed in Figures 3-6 for the two different risk-free rate benchmarks under consideration. The special case relative to SP500 market benchmark is dealt with in Table 17, which exhibits $T^{\prime}$ Treynor ratio and related beta $\beta^{\prime}$ respectively.

Table 5

Classic and New Sharpe Ratios Ranked by Increasing Order

\begin{tabular}{|c|c|c|c|c|c|c|}
\hline \multirow{2}{*}{$\begin{array}{l}\text { DJHF } \\
\text { index rank }\end{array}$} & \multicolumn{2}{|c|}{$S$} & \multicolumn{2}{|c|}{$S^{*}$} & \multicolumn{2}{|r|}{$S^{* *}$} \\
\hline & $r_{3 M}$ & DJCBTI & $r_{3 M}$ & DJCBTI & $r_{3 M}$ & DJCBTI \\
\hline 1 & SB_CA & SB_CA & SB_EMN & SB_EMN & SB_CA & SB_CA \\
\hline 2 & BPI_BX & BPI_BX & SB_CA & SB_CA & BPI_BX & SB_EMN \\
\hline 3 & SB_EMN & SB_EMN & BPI_BX & BPI_BX & SB_EMN & BPI_BX \\
\hline 4 & SB_ELS & BPI_AX & SB_DS & SB_ELS & SB_ELS & SB_ELS \\
\hline 5 & BPI & BPI & SB_MA & SB_DS & BPI & BPI \\
\hline 6 & SB_DS & SB_DS & SB_ELS & SB_MA & SB_DS & SB_DS \\
\hline 7 & BPI_AX & SB_ELS & SB_ED & SB_ED & BPI_AX & SB_ED \\
\hline 8 & SB_ED & SB_ED & BPI_AX & BPI & SB_ED & BPI_AX \\
\hline 9 & SB_MA & SB_MA & BPI & BPI_AX & SB_MA & SB_MA \\
\hline
\end{tabular}

Table 6

Classic Treynor Ratios vs. the Three-Month Rate and Market Benchmarks

\begin{tabular}{llllllll}
\hline DJHF index & DJIA & DJC & SP500 & DWCF & $\begin{array}{l}\text { Lehman Agg. } \\
\text { NAV }\end{array}$ & $\begin{array}{l}\text { Lehman } \\
\text { Comp. }\end{array}$ & $\begin{array}{l}\text { iBoxx IG } \\
\text { NAV }\end{array}$ \\
\hline SB_CA & 0.0355 & 0.0356 & 0.0360 & 0.0364 & -0.0517 & -0.6835 & -0.0152 \\
SB_DS & 0.1104 & 0.1213 & 0.1142 & 0.1094 & -0.1428 & -5.7053 & -0.4497 \\
SB_ED & 0.0650 & 0.0716 & 0.0661 & 0.0654 & -0.0953 & -4.8492 & -0.1593 \\
SB_EMN & 0.0153 & 0.0147 & 0.0162 & 0.0167 & -0.0048 & 0.2089 & -0.0067 \\
SB_MA & 0.1935 & 0.2070 & 0.1908 & 0.1852 & -0.2003 & -7.4657 & -0.2597 \\
SB_ELS & 0.0454 & 0.0497 & 0.0445 & 0.0436 & -0.0511 & -9.4212 & -0.0902 \\
BPI & 0.0594 & 0.0653 & 0.0593 & 0.0582 & -0.0574 & -7.7053 & -0.1135 \\
BPI_AX & 0.0817 & 0.0892 & 0.0831 & 0.0815 & -0.0797 & -8.7404 & -0.1791 \\
BPI_BX & 0.0038 & 0.0042 & 0.0038 & 0.0038 & -0.0036 & -0.2248 & -0.0078 \\
\hline
\end{tabular}

First, consider Treynor ratios relative to the three-month risk-free rate benchmark. As regards classic ratios, DJIA, DJC, SP500 and DWCF benchmark-based computations yield the same ranking of hedge fund indexes for

\footnotetext{
${ }^{37}$ Although we know all the values may not be interesting depending on the hedge fund strategy under consideration, we provide the obtained results for all the selected market benchmarks as a rough guide. This way of processing is also supported by the non-parametric correlation matrix whose correlation coefficients are generally significant at a one or five percent bilateral student test level (see Appendix A).
} 
100\% of cases. This number falls to $11.1111 \%$ when we use the Lehman Aggregate NAV, Lehman Composite and iBoxx Investment Grade NAV indicators as market benchmarks. Analogously, we obtain the same ranking in 100 percent of cases for new Treynor ratios whatever the market benchmark under consideration except for the Lehman Aggregate NAV and DJC (when applied to the second new Treynor ratio $T^{* *}$ ) market benchmarks. Specifically, the ranking inferred from Lehman Aggregate NAV indicator coincides only with other benchmark-based new Treynor ratios in only $11.1111 \%$ of cases. And this percentage rises up to $77.7778 \%$ in the case of DJC stock market benchmark. However, switching from the classic Treynor ratio to the modified one triggers little structural change in hedge fund styles' ranking. Indeed, most of the new rankings (i.e., rankings implied by the new modified ratios) can fit the old ranking (i.e., rankings implied by classic ratios) with regard to all market indexes except Lehman Composite and iBoxx Investment Grade NAV ones. However, this number falls to $11.1111 \%$ relative to the Lehman Composite and iBoxx Investment Grade NAV cases (i.e., market benchmark; see Table 16).

Table 7

Classic Treynor Ratios vs. DJCBTI Return and Market Benchmarks

\begin{tabular}{|c|c|c|c|c|c|c|c|}
\hline DJHF index & DJIA & DJC & SP500 & DWCF & $\begin{array}{l}\text { Lehman Agg. } \\
\text { NAV }\end{array}$ & $\begin{array}{l}\text { Lehman } \\
\text { Comp. }\end{array}$ & $\begin{array}{l}\text { iBoxx IG } \\
\text { NAV }\end{array}$ \\
\hline SB_CA & 0.0594 & 0.1643 & 0.0825 & 0.0903 & -0.0022 & -2.7984 & -0.0032 \\
\hline SB_DS & 0.0771 & 0.0952 & 0.0842 & 0.0839 & -0.0113 & -2.6423 & -0.0153 \\
\hline SB_ED & 0.0602 & 0.0701 & 0.0632 & 0.0632 & -0.0166 & -3.0693 & -0.0225 \\
\hline SB_EMN & 0.0380 & 0.0475 & 0.0428 & 0.0444 & -0.0038 & -4.1228 & -0.0050 \\
\hline SB_MA & 0.1277 & 0.1526 & 0.1346 & 0.1343 & -0.0209 & -4.0597 & -0.0275 \\
\hline SB_ELS & 0.0455 & 0.0516 & 0.0458 & 0.0452 & -0.0162 & -4.3844 & -0.0228 \\
\hline BPI & 0.0544 & 0.0650 & 0.0572 & 0.0572 & -0.0103 & -2.8466 & -0.0141 \\
\hline BPI_AX & 0.0643 & 0.0786 & 0.0694 & 0.0699 & -0.0097 & -2.7416 & -0.0133 \\
\hline BPI_BX & 0.0246 & 0.0302 & 0.0265 & 0.0267 & -0.0037 & -0.8958 & -0.0050 \\
\hline
\end{tabular}

Table 8

New Treynor Ratios T*v. Three-Month Rate and Market Benchmarks

\begin{tabular}{llllllll}
\hline DJHF index & DJIA & DJC & SP500 & DWCF & $\begin{array}{l}\text { Lehman Agg. } \\
\text { NAV }\end{array}$ & $\begin{array}{l}\text { Lehman } \\
\text { Comp. }\end{array}$ & $\begin{array}{l}\text { iBoxx IG } \\
\text { NAV }\end{array}$ \\
\hline SB_CA & 0.0337 & 0.0341 & 0.0373 & 0.0383 & -0.0520 & 0.4930 & 0.0038 \\
SB_DS & 0.1179 & 0.1274 & 0.1322 & 0.1357 & -0.1327 & 1.0683 & 0.0128 \\
SB_ED & 0.0654 & 0.0724 & 0.0728 & 0.0748 & -0.0928 & 0.7394 & 0.0073 \\
SB_EMN & 0.0176 & 0.0164 & 0.0199 & 0.0204 & -0.0049 & 0.1273 & 0.0019 \\
SB_MA & 0.1952 & 0.2106 & 0.2175 & 0.2233 & -0.1994 & 2.1876 & 0.0217 \\
SB_ELS & 0.0457 & 0.0502 & 0.0509 & 0.0522 & -0.0511 & 0.5160 & 0.0051 \\
BPI & 0.0606 & 0.0667 & 0.0676 & 0.0694 & -0.0571 & 0.6508 & 0.0067 \\
BPI_AX & 0.0843 & 0.0920 & 0.0942 & 0.0967 & -0.0788 & 0.8661 & 0.0093 \\
BPI_BX & 0.0039 & 0.0043 & 0.0044 & 0.0045 & -0.0035 & 0.0404 & 0.0004 \\
\hline
\end{tabular}

Second, consider Treynor ratios relative to DJCBTI return as a risk-free rate benchmark. As regards classic ratios, the various benchmark-based computations yield very heterogeneous rankings of hedge fund indexes. Differently, new Treynor ratios provide the same hedge funds' rankings in 100 percent of cases with regard to most market benchmarks. However, this percentage falls to 22.2222 when we consider the ratios computed 
relative to the Lehman Aggregate NAV indicator as a market benchmark whereas it rises up to $66.6667 \%$ in the case of DJC stock market benchmark (when applied to the first new Treynor ratio $T^{*}$ ). Finally, the rankings obtained from the new Treynor ratios differ structurally from the ones inferred from the classic Treynor ratio. The lowest matching performance between rankings is obtained for iBoxx IG NAV and DJC market benchmarks with a level of $11.1111 \%$ (see Table 16).

Table 9

New Treynor Ratios T*vs. DJCBTI Return and Market Benchmarks

\begin{tabular}{llllllll}
\hline DJHF index & DJIA & DJC & SP500 & DWCF & $\begin{array}{l}\text { Lehman Agg. } \\
\text { NAV }\end{array}$ & $\begin{array}{l}\text { Lehman } \\
\text { Comp. }\end{array}$ & $\begin{array}{l}\text { iBoxx IG } \\
\text { NAV }\end{array}$ \\
\hline SB_CA & 0.0740 & 0.2714 & 0.0844 & 0.0867 & -0.0021 & 0.4277 & 0.0076 \\
SB_DS & 0.0821 & 0.1003 & 0.0919 & 0.0944 & -0.0111 & 0.7528 & 0.0089 \\
SB_ED & 0.0614 & 0.0715 & 0.0685 & 0.0703 & -0.0164 & 0.6600 & 0.0068 \\
SB_EMN & 0.0412 & 0.0511 & 0.0462 & 0.0475 & -0.0037 & 0.3574 & 0.0045 \\
SB_MA & 0.1317 & 0.1575 & 0.1471 & 0.1511 & -0.0207 & 1.3545 & 0.0145 \\
SB_ELS & 0.0462 & 0.0525 & 0.0515 & 0.0529 & -0.0161 & 0.5044 & 0.0051 \\
BPI & 0.0564 & 0.0671 & 0.0629 & 0.0646 & -0.0102 & 0.5723 & 0.0062 \\
BPI_AX & 0.0673 & 0.0820 & 0.0752 & 0.0773 & -0.0096 & 0.6576 & 0.0074 \\
BPI_BX & 0.0258 & 0.0316 & 0.0288 & 0.0296 & -0.0036 & 0.2516 & 0.0028 \\
\hline
\end{tabular}

Table 10

New Treynor Ratios T** vs. Three-Month Rate and Market Benchmarks

\begin{tabular}{llllllll}
\hline DJHF index & DJIA & DJC & SP500 & DWCF & $\begin{array}{l}\text { Lehman Agg. } \\
\text { NAV }\end{array}$ & $\begin{array}{l}\text { Lehman } \\
\text { Comp. }\end{array}$ & $\begin{array}{l}\text { iBoxx IG } \\
\text { NAV }\end{array}$ \\
\hline SB_CA & 0.0370 & 0.0374 & 0.0408 & 0.0419 & -0.0521 & 0.5131 & 0.0041 \\
SB_DS & 0.1394 & 0.1449 & 0.1569 & 0.1614 & -0.2325 & 2.2295 & 0.0157 \\
SB_ED & 0.0655 & 0.0728 & 0.0730 & 0.0749 & -0.0984 & 0.9775 & 0.0073 \\
SB_EMN & 0.0535 & 0.0385 & 0.0608 & 0.0627 & -0.0052 & 0.9203 & 0.0061 \\
SB_MA & 0.1958 & 0.2137 & 0.2182 & 0.2242 & -0.1997 & 2.9306 & 0.0219 \\
SB_ELS & 0.0458 & 0.0506 & 0.0510 & 0.0524 & -0.0511 & 0.6833 & 0.0051 \\
BPI & 0.0615 & 0.0684 & 0.0686 & 0.0705 & -0.0573 & 0.9323 & 0.0069 \\
BPI_AX & 0.0873 & 0.0968 & 0.0977 & 0.1004 & -0.0797 & 1.3417 & 0.0098 \\
BPI_BX & 0.0041 & 0.0046 & 0.0046 & 0.0047 & -0.0036 & 0.0625 & 0.0005 \\
\hline
\end{tabular}

Table 11

New Treynor Ratios T** vs. DJCBTI Return and Market Benchmarks

\begin{tabular}{|c|c|c|c|c|c|c|c|}
\hline DJHF index & DJIA & DJC & SP500 & DWCF & $\begin{array}{l}\text { Lehman Agg. } \\
\text { NAV }\end{array}$ & $\begin{array}{l}\text { Lehman } \\
\text { Comp. }\end{array}$ & $\begin{array}{l}\text { iBoxx IG } \\
\text { NAV }\end{array}$ \\
\hline SB_CA & -0.0986 & -0.0211 & -0.1136 & -0.1173 & -0.0022 & -1.8314 & -0.0113 \\
\hline SB_DS & 0.0951 & 0.1165 & 0.1070 & 0.1100 & -0.0113 & 1.5153 & 0.0107 \\
\hline SB_ED & 0.0622 & 0.0729 & 0.0695 & 0.0714 & -0.0166 & 0.9435 & 0.0070 \\
\hline SB_EMN & 0.0527 & 0.0701 & 0.0594 & 0.0612 & -0.0038 & 0.8549 & 0.0059 \\
\hline SB_MA & 0.1363 & 0.1660 & 0.1525 & 0.1567 & -0.0209 & 2.0946 & 0.0153 \\
\hline SB_ELS & 0.0466 & 0.0533 & 0.0520 & 0.0534 & -0.0161 & 0.7025 & 0.0052 \\
\hline BPI & 0.0588 & 0.0710 & 0.0658 & 0.0676 & -0.0102 & 0.9064 & 0.0066 \\
\hline BPI_AX & 0.0724 & 0.0899 & 0.0811 & 0.0834 & -0.0097 & 1.1296 & 0.0081 \\
\hline BPI_BX & 0.0277 & 0.0348 & 0.0311 & 0.0319 & -0.0037 & 0.4326 & 0.0031 \\
\hline
\end{tabular}

Third, consider the special case of Treynor ratio when SP500 index is the selected market benchmark as 
represented by Table 17. As regards Treynor ratio relative to DJCBTI return and the three-month risk-free rate, we get the same ranking of hedge fund indexes in 55.5556 percent of cases. Strikingly, this percentage rises to 100 percent when we consider the corresponding beta values.

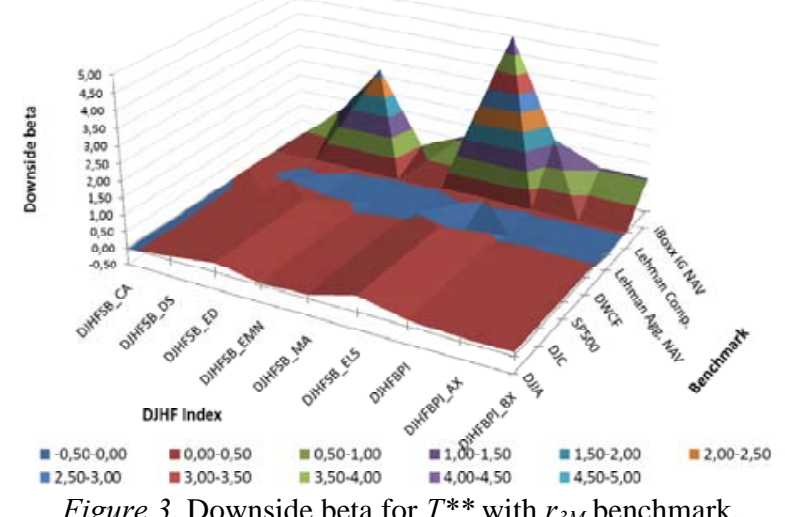

Figure 3. Downside beta for $T^{* *}$ with $r_{3 M}$ benchmark.

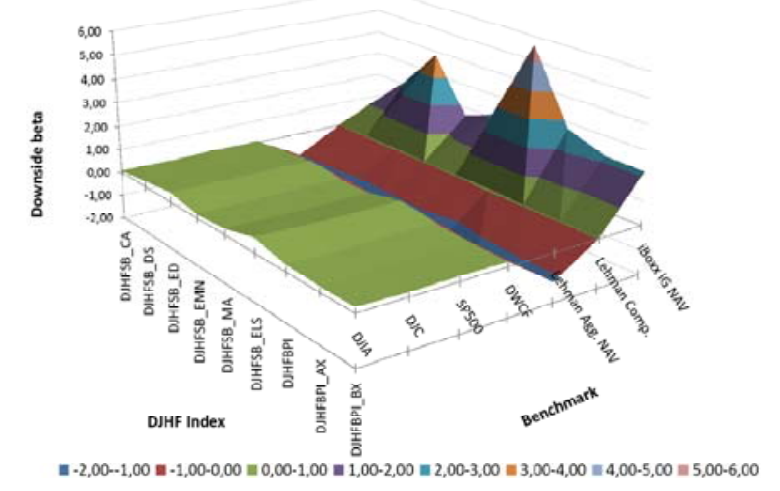

Figure 5. Downside beta for $T^{* *}$ with DJCBTI benchmark.

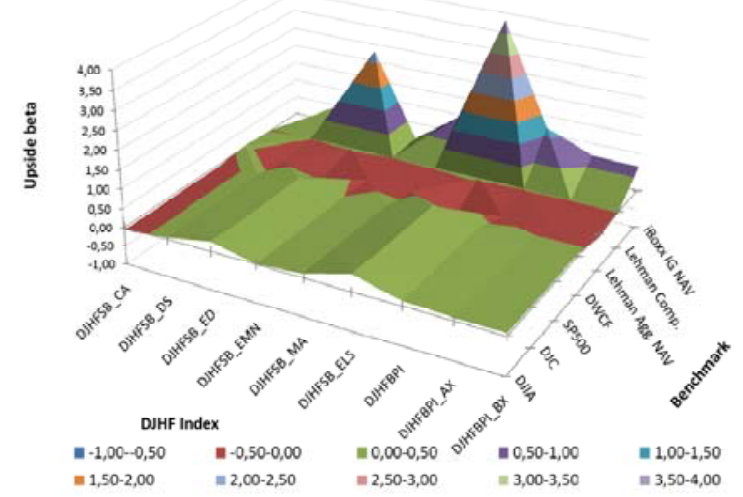

Figure 4. Upside beta for $T^{* *}$ with $r_{3 M}$ benchmark.

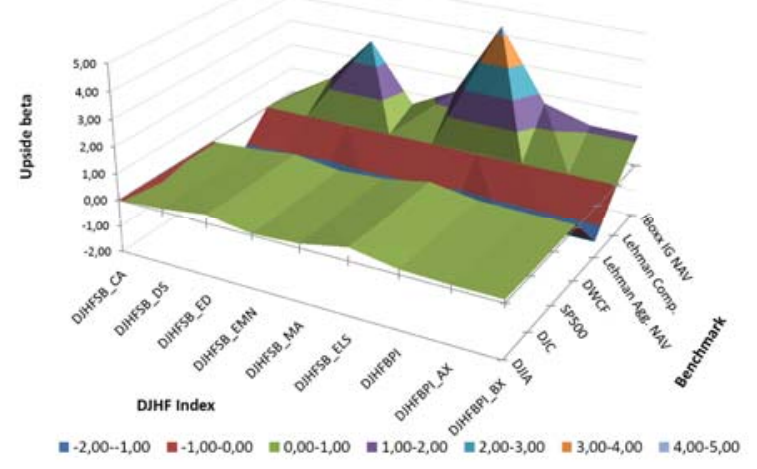

Figure 6. Upside beta for $T^{* *}$ with DJCBTI benchmark.

Table 12

Classic Betas vs. Three-Month Rate and Market Benchmarks

\begin{tabular}{lllllllc}
\hline DJHF index & DJIA & DJC & SP500 & DWCF & $\begin{array}{l}\text { Lehman Agg. } \\
\text { NAV }\end{array}$ & $\begin{array}{l}\text { Lehman } \\
\text { Comp. }\end{array}$ & $\begin{array}{l}\text { iBoxx IG } \\
\text { NAV }\end{array}$ \\
\hline SB_CA & -0.0517 & -0.0515 & -0.0508 & -0.0503 & 0.0355 & 0.0027 & 0.1205 \\
SB_DS & 0.0863 & 0.0786 & 0.0834 & 0.0871 & -0.0667 & -0.0017 & -0.0212 \\
SB_ED & 0.2781 & 0.2521 & 0.2732 & 0.2760 & -0.1895 & -0.0037 & -0.1134 \\
SB_EMN & 0.0326 & 0.0339 & 0.0309 & 0.0299 & -0.1052 & 0.0024 & -0.0746 \\
SB_MA & 0.1149 & 0.1074 & 0.1165 & 0.1201 & -0.1110 & -0.0030 & -0.0856 \\
SB_ELS & 0.4658 & 0.4254 & 0.4747 & 0.4847 & -0.4137 & -0.0022 & -0.2343 \\
BPI & 0.1558 & 0.1418 & 0.1561 & 0.1592 & -0.1612 & -0.0012 & -0.0816 \\
BPI_AX & 0.0975 & 0.0893 & 0.0958 & 0.0978 & -0.0999 & -0.0009 & -0.0445 \\
BPI_BX & 0.0953 & 0.0867 & 0.0944 & 0.0962 & -0.1019 & -0.0016 & -0.0463 \\
\hline
\end{tabular}

Finally, estimated classic and new beta values yield the same ranking of hedge fund index returns whatever the risk-free rate benchmark under consideration. This feature comes probably from the fact that hedge fund index returns and market benchmarks exhibit generally the same stylized facts such as negative skewness and positive excess kurtosis. Moreover, there exist noticeable differences across hedge fund indexes' betas when we 
modify the risk-free rate benchmark. However, the sign of estimated betas is generally the same so that we get the same result interpretation except for the case of the hedge fund convertible arbitrage strategy ${ }^{38}$ on one side, and the cases of Lehman Composite and iBoxx IG NAV benchmarks on the other side. If we consider the statistics embedded in the computation of the classic beta à la Sharpe as appropriate risk measures, the sensitivity of hedge fund strategies' performance to market and credit risks depends on the market/credit benchmarks under consideration. Moreover, if we refer to the empirical facts describing hedge fund strategies, we can add the following comments about modified beta estimates. Whatever the risk-free rate benchmark under consideration, DJHFSB_ED, DJHFSB_ELS and DJHFSB_MA indexes exhibit indeed sensitivity to both equity and credit markets. Concerning the sensitivity of DJHFSB_CA and DJHFSB_DS indexes to credit risk, the DJCBTI interest rate benchmark seems more relevant to assess such a risk dependency. Concerning the low sensitivity of DJHFSB_CA and DJHFSB_EMN indexes to equity risk, obtained results favor slightly the three-month risk-free rate as an interest rate benchmark for beta-related computations. Therefore, empirical facts are translated into obtained modified beta estimates, which is not generally the case for classic beta estimates.

Table 13

Classic Betas vs. DJCBTI Return and Market Benchmarks

\begin{tabular}{llllllll}
\hline DJHF index & \multirow{2}{*}{ DJIA } & \multirow{2}{*}{ DJC } & \multirow{2}{*}{ SP500 } & \multirow{2}{*}{ DWCF } & $\begin{array}{l}\text { Lehman Agg. } \\
\text { NAV }\end{array}$ & $\begin{array}{l}\text { Lehman } \\
\text { Comp. }\end{array}$ & $\begin{array}{l}\text { iBoxx IG } \\
\text { NAV }\end{array}$ \\
\hline SB_CA & 0.0409 & 0.0148 & 0.0295 & 0.0269 & -1.1213 & -0.0009 & -0.7571 \\
SB_DS & 0.1789 & 0.1448 & 0.1637 & 0.1643 & -1.2235 & -0.0052 & -0.8988 \\
SB_ED & 0.3707 & 0.3184 & 0.3535 & 0.3532 & -1.3463 & -0.0073 & -0.9910 \\
SB_EMN & 0.1252 & 0.1002 & 0.1112 & 0.1072 & -1.2620 & -0.0012 & -0.9521 \\
SB_MA & 0.2075 & 0.1737 & 0.1968 & 0.1973 & -1.2678 & -0.0065 & -0.9632 \\
SB_ELS & 0.5584 & 0.4917 & 0.5551 & 0.5619 & -1.5705 & -0.0058 & -1.1119 \\
BPI & 0.2484 & 0.2081 & 0.2364 & 0.2364 & -1.3180 & -0.0048 & -0.9591 \\
BPI_AX & 0.1901 & 0.1556 & 0.1761 & 0.1750 & -1.2567 & -0.0045 & -0.9221 \\
BPI_BX & 0.1879 & 0.1530 & 0.1747 & 0.1734 & -1.2587 & -0.0052 & -0.9239 \\
\hline
\end{tabular}

Table 14

Modified Betas vs. Three-Month Rate and Market Benchmarks

\begin{tabular}{|c|c|c|c|c|c|c|c|}
\hline DJHF index & DJIA & DJC & SP500 & DWCF & $\begin{array}{l}\text { Lehman Agg. } \\
\text { NAV }\end{array}$ & $\begin{array}{l}\text { Lehman } \\
\text { Comp. }\end{array}$ & $\begin{array}{l}\text { iBoxx IG } \\
\text { NAV }\end{array}$ \\
\hline SB_CA & -0.0544 & -0.0537 & -0.0491 & -0.0478 & 0.0353 & -0.0037 & -0.4783 \\
\hline SB_DS & 0.0808 & 0.0748 & 0.0721 & 0.0702 & -0.0718 & 0.0089 & 0.7425 \\
\hline SB_ED & 0.2763 & 0.2495 & 0.2481 & 0.2416 & -0.1946 & 0.0244 & 2.4818 \\
\hline SB_EMN & 0.0284 & 0.0305 & 0.0252 & 0.0245 & -0.1025 & 0.0039 & 0.2688 \\
\hline SB_MA & 0.1139 & 0.1056 & 0.1022 & 0.0996 & -0.1115 & 0.0102 & 1.0240 \\
\hline SB_ELS & 0.4626 & 0.4207 & 0.4153 & 0.4044 & -0.4134 & 0.0410 & 4.1559 \\
\hline BPI & 0.1527 & 0.1388 & 0.1369 & 0.1334 & -0.1623 & 0.0142 & 1.3789 \\
\hline BPI_AX & 0.0945 & 0.0866 & 0.0846 & 0.0824 & -0.1011 & 0.0092 & 0.8567 \\
\hline BPI_BX & 0.0923 & 0.0839 & 0.0827 & 0.0805 & -0.1039 & 0.0090 & 0.8374 \\
\hline
\end{tabular}

Consequently, accounting for asymmetric features in hedge fund returns triggers more or less structural changes in the rankings inferred from Treynor ratio. Specifically, the ranking remains unchanged for the stock

38 The previous exception does not apply to the special case of SP500, which is illustrated by $\beta^{\prime}$ values among others. 
market benchmarks whereas it changes structurally for most bond market benchmarks when the risk-free rate benchmark is the three-month U.S. treasury rate. The structural change is more pronounced when the risk-free rate benchmark under consideration is DJCBTI index. Of course, such benchmark-based results need to be envisioned in the light of their coherency with the hedge fund style under consideration (see the corresponding correlation matrix in the Appendix A). Moreover, obtained modified beta estimates seem to stick to the stylized features describing the common strategies at use within the hedge fund industry.

Table 15

Modified Betas vs. DJCBTI Return and Market Benchmarks

\begin{tabular}{llllllll}
\hline DJHF index & \multirow{2}{*}{ DJIA } & \multirow{2}{*}{ DJC } & \multirow{2}{*}{ SP500 } & DWCF & $\begin{array}{l}\text { Lehman Agg. } \\
\text { NAV }\end{array}$ & $\begin{array}{l}\text { Lehman } \\
\text { Comp. }\end{array}$ & $\begin{array}{l}\text { iBoxx IG } \\
\text { NAV }\end{array}$ \\
\hline SB_CA & 0.0329 & 0.0090 & 0.0288 & 0.0280 & -1.1328 & 0.0057 & 0.3215 \\
SB_DS & 0.1680 & 0.1375 & 0.1500 & 0.1460 & -1.2398 & 0.0183 & 1.5423 \\
SB_ED & 0.3635 & 0.3122 & 0.3260 & 0.3174 & -1.3626 & 0.0338 & 3.2817 \\
SB_EMN & 0.1157 & 0.0932 & 0.1031 & 0.1004 & -1.2706 & 0.0133 & 1.0686 \\
SB_MA & 0.2011 & 0.1682 & 0.1801 & 0.1754 & -1.2796 & 0.0196 & 1.8238 \\
SB_ELS & 0.5498 & 0.4833 & 0.4932 & 0.4803 & -1.5814 & 0.0504 & 4.9557 \\
BPI & 0.2400 & 0.2014 & 0.2148 & 0.2092 & -1.3304 & 0.0236 & 2.1787 \\
BPI_AX & 0.1817 & 0.1492 & 0.1625 & 0.1582 & -1.2692 & 0.0186 & 1.6565 \\
BPI_BX & 0.1796 & 0.1466 & 0.1606 & 0.1564 & -1.2719 & 0.0184 & 1.6372 \\
\hline
\end{tabular}

Table 16

Comparing the Rankings 'Similarity Between Classic and New Treynor Ratios Across Hedge Fund Indexes

\begin{tabular}{|c|c|c|c|c|}
\hline \multirow{2}{*}{$\begin{array}{l}\% \\
\text { DJHF index }\end{array}$} & \multicolumn{2}{|c|}{$r_{3 M}$} & \multicolumn{2}{|c|}{ DJCBTI } \\
\hline & $T^{*}$ & $T^{* *}$ & $T^{*}$ & $T^{* *}$ \\
\hline DJIA & 100.0000 & 66.6667 & 66.6667 & 55.5556 \\
\hline DJC & 100.0000 & 77.7778 & 100.0000 & 11.1111 \\
\hline SP500 & 100.0000 & 66.6667 & 100.0000 & 33.3333 \\
\hline DWCF & 100.0000 & 66.6667 & 77.7778 & 22.2222 \\
\hline Lehman Agg. NAV & 100.0000 & 77.7778 & 100.0000 & 100.0000 \\
\hline Lehman Comp. & 11.1111 & 11.1111 & 33.3333 & 33.3333 \\
\hline iBoxx IG NAV & 11.1111 & 11.1111 & 11.1111 & 11.1111 \\
\hline
\end{tabular}

Table 17

Special Case of Treynor Ratio for SP500 Market Benchmark

\begin{tabular}{lcccc}
\hline \multirow{2}{*}{ DJHF index } & \multicolumn{3}{c}{$r_{3 M}$} & \multicolumn{2}{c}{ DJCBTI } \\
\cline { 2 - 4 } & $T^{\prime}$ & $\beta^{\prime}$ & $T^{\prime}$ & $\beta^{\prime}$ \\
\hline SB_CA & -0.3316 & $-1.6392 \mathrm{E}-04$ & -8.6083 & $-9.7603 \mathrm{E}-05$ \\
SB_DS & 8.8028 & $2.0673 \mathrm{E}-04$ & 9.5429 & $2.7304 \mathrm{E}-04$ \\
SB_ED & 3.5028 & $7.0519 \mathrm{E}-04$ & 4.2203 & $7.7151 \mathrm{E}-04$ \\
SB_EMN & 2.8433 & $8.9943 \mathrm{E}-05$ & 6.6658 & $1.5626 \mathrm{E}-04$ \\
SB_MA & 7.1609 & $3.0333 \mathrm{E}-04$ & 8.0022 & $3.6964 \mathrm{E}-04$ \\
SB_ELS & 2.6132 & $1.2240 \mathrm{E}-03$ & 3.0879 & $1.2903 \mathrm{E}-03$ \\
BPI & 3.7637 & $3.9664 \mathrm{E}-04$ & 4.9221 & $4.6295 \mathrm{E}-04$ \\
BPI_AX & 5.1651 & $2.4841 \mathrm{E}-04$ & 6.5737 & $3.1473 \mathrm{E}-04$ \\
BPI_BX & 2.8947 & $2.3418 \mathrm{E}-04$ & 4.8711 & $3.0049 \mathrm{E}-04$ \\
\hline
\end{tabular}


Discussing measures' appropriateness. As a back-test process, we compute the non-parametric correlation coefficients (i.e., Kendall association measure) between our various return statistics and observed performance ratios across the various hedge fund indexes under consideration. This way, we control for cross section adequacy of performance measures relative to average realized returns and corresponding skewness and excess kurtosis. To get a clear view, we display in Figure 7 the various correlations computed as increasing functions of the correlation between performance measures and return skewness. Computations show indeed heterogeneous results, which need specific criteria to filter them out.

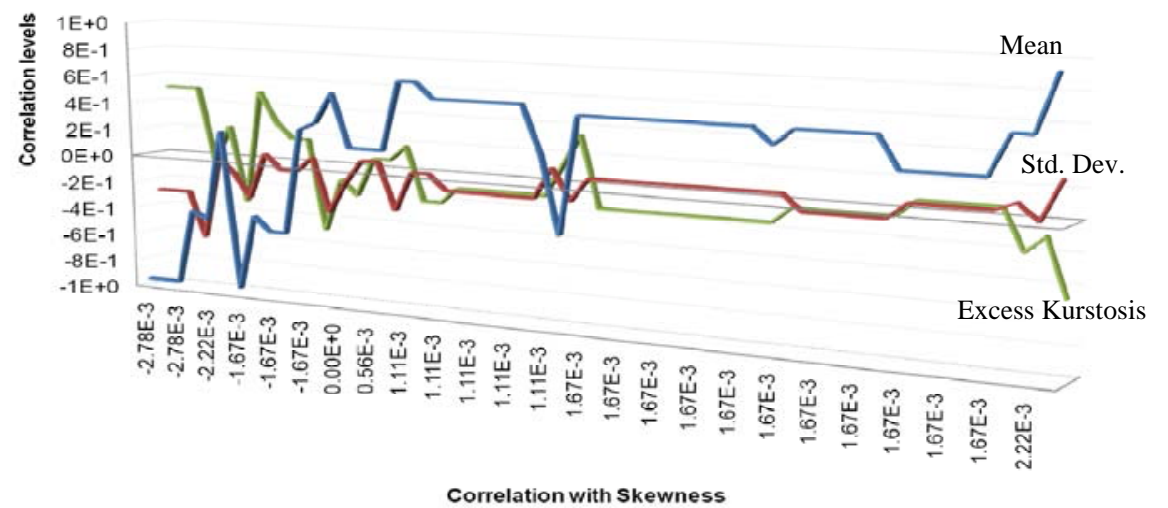

Figure 7. Nonparametric correlation between performance ratios and hedge fund return statistics.

For example, the higher the skewness is, the better it is for hedge fund performance in the light of an increasing average historical return. Such stylized fact is all the more emphasized when the excess kurtosis is high (i.e., heavy distribution tail). Therefore, an investor focusing on skewness will consider performance measures exhibiting a positive correlation with hedge fund return skewness so as to catch the cross section properties of hedge fund performance. Of course, such performance ratios need to be positively correlated with the historical average return across hedge funds. Moreover, if distribution tails' heaviness is also a concern to the investor, the positive correlation between performance measures and returns' excess kurtosis needs to be taken into account. Consequently, the investor's focus is to select coherent and consistent performance ratios, which exhibit at least positive correlations with hedge fund returns' mean, skewness and excess kurtosis (i.e., admissible ratios). Hence, one way to select the optimal performance measure to apply is to build a score function accounting for the features above-mentioned. For example, one could decide to build a score function corresponding to the arithmetic mean of the correlations between the considered performance measures on one side, and corresponding mean, skewness and excess kurtosis values across hedge funds on the other side. Such computation is held provided that all three correlations are positive and assumes that investors attribute the same significance to average return, and corresponding skewness and excess kurtosis. We run such a score function under the three positive-correlation scenario and display the results in Table 18.

Admissible ratios consist of Treynor-based performance measures where the risk-free rate benchmark is simply the DJCBTI index. Optimality would advise to consider the maximum score, which yields T_DJCBTI_SP500, T*_DJCBTI_DJIA, T*_DJCBTI_SP500, T*_DJCBTI_DWCF, and T*_DJCBTI_iBoxx IG 
NAV ratios. The final choice will rely on the global nature of cross section returns (i.e., mixing market benchmarks) so as to rank hedge fund returns’ performance. Basically, the first modified version of Treynor ratio performs very well.

Table 18

Score of Admissible Performance Measures

\begin{tabular}{ll}
\hline Market and risk-free rate benchmarks, and performance ratio & Score \\
\hline T_DJCBTI_DJC & 0.0926 \\
T_DJCBTI_SP500 & 0.1667 \\
T_DJCBTI_DWCF & 0.1481 \\
T'_DJCBTI & 0.1296 \\
T*_DJCBTI_DJIA & 0.1667 \\
T*_DJCBTI_DJC & 0.0926 \\
T*_DJCBTI_SP500 & 0.1667 \\
T*_DJCBTI_DWCF & 0.1667 \\
T*_DJCBTI_iBoxx IG NAV & 0.1667 \\
\hline
\end{tabular}

\section{Conclusion}

Hedge funds allow for widening the investment opportunity set, portfolio diversification, and competitive risk-return profiles among others. Moreover, they apply specific investment policies and bear particular risks (e.g., different return volatility profiles such as low, moderate, high or variable), which depend on their corresponding investment style. The investment style they may apply often generates optional underlying return features and non-normality patterns. Indeed, non-normality has now become a common market feature.

We proposed to account for such asymmetric and non-Gaussian features while modifying two classical performance indexes, namely Sharpe and Treynor ratios. We adjusted these two classic risk-adjusted performance measures for skew risk while making them homogeneous in terms of potential right and left skews in return time series. The asymmetry between the proportions of upside and downside deviations from the mean is closely related to skewness whereas the respective magnitudes of upside and downside deviations are closely linked with kurtosis. Indeed, skewness statistic is an important investment parameter since market participants trade expected returns for their respective skewness (Canela \& Collazo, 2007).

We found little differences in terms of hedge fund styles' ranking when considering either the three-month treasury rate or the DJCBTI return as a risk-free rate. However, modifying the classic performance measures to account for skewness and non-normality in return time series induces a structural change in the obtained Dow Jones hedge fund indexes' ranking.

But nowadays the hedge fund community is more pointing at the means to hire and motivate skilled managers (e.g., rising hedge fund costs) and upgrading the risk control processes currently at stake. Indeed, the current hedge fund debate focuses on how to discriminate between skilled and lucky managers. The hedge fund industry acknowledges officiously that skilled managers are far more numerous than lucky ones. But the frontier between both classes of managers remains far from being evident.

\section{References}

Ackermann, C., McEnally, R., \& Ravenscrat, D. (1999). The performance of hedge funds' risk, returns and incentives. Journal of 
Finance, 54(3), 833-874.

Agarwal, V., \& Naik, N. (2004). Risks and portfolio decisions involving hedge funds. Review of Financial Studies, 17(1), 63-98.

Baquero, G., Horst, J. T., \& Verbeek, M. (2005). Survival, look-ahead bias and the persistence in hedge fund performance. Journal of Financial and Quantitative Analysis, 40(3), 493-517.

Benefield, J. D., Anderson, R. I., \& Zumpano, L. V. (2007). Does the composition of the market portfolio matter for performance rankings of post-1986 equity REITs? Journal of Real Estate Portfolio Management, 13(3), 191-204.

Black, K. H. (2006). Improving the hedge fund risk exposures by hedging equity market volatility, or how the VIX strategy ate my kurtosis. Journal of Trading, 1(2), 6-15.

Boyson, N. M. (2003). Why do experienced hedge fund managers have lower returns? SSRN Working paper. Retrieved from http://www.ssrn.com/abstract $=470182$

Brooks, C., \& Kat, H. (2002). The statistical properties of hedge fund returns. Journal of Alternative Investments, 5(2), 26-44.

Brown, S. J., Gallagher, D. R., Steenbeek, O., \& Swan, P. L. (2004). Double or nothing: Patterns of equity fund holdings and transactions. Working paper, Stern Asset Management Research Group, New York University.

Canela, M. E., \& Collazo, E. P. (2007). Portfolio selection with skewness in emerging market industries. Emerging Markets Review, $8(3), 230-250$.

Carretta, A., \& Mattarocci, G. (2009). The performance evaluation of hedge funds: A comparison of different approaches using European data. Forthcoming in Merger and Acquisitions in European Banking (F. Fiordelisi, Eds.). Palgrave McMillan, UK.

Chadwick, S. (2006). Can the VIX signal market direction? Credit Suisse Report, Quantitative Trading and Derivatives Strategy.

Dash, S., \& Moran, M. T. (2005). VIX as a companion for hedge fund portfolios. Journal of Alternative Investments, 8(3), 75-80.

Eling, M. (2006). Autocorrelation, bias and fat tails: Are hedge funds really attractive investments? Derivatives Use, Trading Regulation, 12(1), 28-47.

Eling, M., \& Schuhmacher, F. (2006). Does the choice of performance measure influence the evaluation of hedge funds? Working paper, 9 th Conference of The Swiss Society For Financial Market Research, Zurich (April).

Feldman, B., \& Roy, D. (2005). Passive options-based investment strategies: The case of CBOE S\&P 500 stocks buywrite index. Journal of Investing, 17(1), 66-83.

Getmansky, M., Lo, A. W., \& Makarov, I. (2004). An econometric model of serial correlation and illiquidity in hedge fund returns. Journal of Financial Economics, 74(3), 529-609.

Goldman, D. (2003). Seeing is not believing: Fund-of-fund and hedge fund risk assessment and transparency, survival and leverage. Working paper, Measurisk working paper series.

Harvey, C., Liechty, J., Liechty, M., \& Müller, P. (2004). Portfolio selection with higher moments. SSRN Working paper. Retrieved from http://www.ssrn.com/abstract=634141

Hodges, S. D. (1998). A generalization of the Sharpe ratio and its applications to valuation bounds and risk measures. Working paper, FORC Preprint 98/88, Financial Options Research Centre, University of Warwick.

Horst, J. T., \& Verbeek, M. (2007). Fund liquidation, self-selection, and look-ahead bias in the hedge fund industry. Review of Finance, 11(4), 605-632.

Hull, J. (2006). Risk management and financial institutions. Upper Saddle River, N.J.: Prentice Hall.

Hull, J. (2007). VAR vs. expected shortfall. Asia Risk, March, 40-41.

Ibbotson, R. G., \& Chen, P. (2005). Sources of hedge fund returns: Alphas, betas, and costs. Yale ICF Working paper No. 05-17, Yale International Center for Finance.

Jobson, J. D., \& Korkie, B. M. (1981). Performance hypothesis testing with the Sharpe and Treynor measures. Journal of Finance, 36(4), 889-908.

Jones, M. (2007). Examination of fund age and size and its impact on hedge fund performance. Derivatives Use, Trading Regulation, 12(4), 342-350.

Kat, H. M. (2005). The danger of mechanical investment decision-making: The case of hedge funds. In G. H. Fong (Ed.), The World of Hedge Funds (Chapter 3, pp. 49-62). New Jersey: World Scientific.

Kat, H. M., \& Menexe, F. (2003). Persistence in hedge fund performance: The true value of a track record. Journal of Alternative Investments, 5(1), 66-72.

Kat, H. M., \& Miffre, J. (2003). Performance evaluation and conditioning information: The case of hedge funds. SSRN Working paper. Retrieved from http://www.ssrn.com/abstract=424368

Khanniche, S. (2008). Evaluation of hedge fund returns' value-at-risk using GARCH models. 5th AFE Conference, Samos (Greece, July). 
Klemkosky, R. (1973). The bias in composite performance measures. Journal of Financial and Quantitative Analysis, 8(3), 505-514.

Lavine, A. (2003). Hedge fund data seriously flawed. Money Management Executive, 11(27), 3.

Lhabitant, F. S., \& Learned, M. (2002). Hedge fund diversification: How much is enough? Journal of Alternative Investments, Winter, 23-49.

Liang, B., \& Park, H. (2007). Risk measures for hedge funds: A cross-sectional approach. European Financial Management, 13(2), 333-370.

Liang, B. (2003). The accuracy of hedge fund returns. Journal of Portfolio Management, 29(3), 111-122.

Madan, D. B., \& McPhail, G. S. (2000). Investing in skews. Journal of Risk Finance, 2(1), 10-18.

Mc Fall Lamm, R. Jr. (2003). Asymmetric returns and optimal hedge fund portfolio. Journal of Alternative Investments, 6(1), 9-21. McMillan, L. G. (2007). Modern portfolio protection. Working paper, Barron’s.

Miller, R. E., \& Gehr, A. K. (1978). Sample size bias and Sharpe's performance measure: A note. Journal of Financial and Quantitative Analysis, 13(5), 943-946.

Moix, P., \& Schmidhuber, C. (2001). Fat tail risk: The case for hedge funds (parts I and II). AIMA Newsletter 9 (September, December).

Roll, R. (1977). Ambiguity when performance is measured by the security market line. Journal of Finance, 33(4), 1051-1069.

Scholz, H., \& Wilkens, M. (2005). Interpreting Sharpe ratios-The market climate bias. SSRN Working paper. Retrieved from http://ssrn.com/abstract $=524842$

Sharpe, W. F. (1994). The Sharpe ratio. Journal of Portfolio Management, 21(1), 49-58.

Sharpe, W. F. (1966). Mutual fund performance. Journal of Business, 39(1), 119-139.

Spurgin, R. (2001). How to game your Sharpe ratio. Journal of Alternative Investments, 4(3), 38-46.

Taleb, N. (2007). The black swan: The impact of the highly improbable, penguin.

Treynor, J. L. (1965). How to rate management of investment funds. Harvard Business Review, 43(1), 63-76.

Veinstein, E., \& Abdulali, A. (2002). Hedge fund transparency: Quantifying valuation bias for illiquid assets. Risk, 15(6), S25-S28.

Weisman, A. B. (2002). Informationless investing and hedge fund performance measurement bias. Journal of Portfolio Management, 28(4), 80-91.

Weisman, A. B., \& Abernathy, J. D. (2000). The dangers of historical hedge fund data. In L. Rahl (Ed.), Risk budgeting. London: Risk Books.

Wermers, R. (2000). Mutual fund performance: An empirical decomposition into stock-picking talent, style, transactions costs, and expenses. Journal of Finance, 55(4), 1655-1703.

Whaley, R. (2002). Risk and return of the CBOE buywrite monthly index. Journal of Derivatives, 10(1), 35-42.

\section{Appendix A}

We propose some useful proofs and concepts in this section, which are interesting and helpful for the understanding of our work.

\section{Outlier's Impact on Sharpe Index}

As mentioned in section 3.1, the existence of an outlier may impact strongly the obtained Sharpe index level. We consider two cases where a positive and a negative outlier (relative to the mean) impact the original hedge fund return time series $\left(P_{t}\right)$. Assume first that the outlier return appears at time $j$ over the studied time horizon, which encompasses $n$ return observations. Then we can rewrite the respective historical mean $\mu$ and variance $\sigma^{2}$ as follows:

$$
\begin{gathered}
\mu=\frac{1}{n} \sum_{t=1}^{n} P_{t}=\frac{1}{n}\left(\sum_{t=1, t \neq j}^{n} P_{t}\right)+\frac{P_{j}}{n} \\
\sigma^{2}=\frac{1}{n} \sum_{t=1}^{n}\left(P_{t}-\mu\right)^{2}=\frac{1}{n} \sum_{t=1, t \neq j}^{n}\left(P_{t}-\mu\right)^{2}+\frac{1}{n}\left(P_{j}-\mu\right)^{2}
\end{gathered}
$$

We label $P_{j}^{+}$and $P_{j}^{-}$respectively the cases where we consider a positive and a negative outlier return such that $P_{j}^{+}$and 
$P_{j}^{-}$are respectively higher and lower than $P_{j}$. The corresponding historical means and variances are labeled $\mu_{+}, \mu_{-}, \sigma_{+}^{2}$ and $\sigma_{-}^{2}$ respectively so that:

$$
\begin{gathered}
\mu_{+}=\frac{1}{n} \sum_{t=1}^{n} P_{t}=\frac{1}{n}\left(\sum_{t=1, t \neq j}^{n} P_{t}\right)+\frac{P_{j}^{+}}{n} \geq \frac{1}{n}\left(\sum_{t=1, t \neq j}^{n} P_{t}\right)+\frac{P_{j}}{n}=\mu \\
\mu_{-}=\frac{1}{n}\left(\sum_{t=1, t \neq j}^{n} P_{t}\right)+\frac{P_{j}^{-}}{n} \leq \frac{1}{n}\left(\sum_{t=1, t \neq j}^{n} P_{t}\right)+\frac{P_{j}}{n}=\mu \\
\sigma_{+}^{2}=\frac{1}{n} \sum_{t=1}^{n}\left(P_{t}-\mu_{+}\right)^{2}=\frac{1}{n} \sum_{t=1}^{n}\left\{\left(P_{t}-\mu\right)-\frac{1}{n}\left(P_{j}^{+}-P_{j}\right)\right\}^{2}=\sigma^{2}+\frac{1}{n^{2}}\left(P_{j}^{+}-P_{j}\right)^{2}>\sigma^{2} \\
\sigma_{-}^{2}=\frac{1}{n} \sum_{t=1}^{n}\left(P_{t}-\mu_{-}\right)^{2}=\frac{1}{n} \sum_{t=1}^{n}\left\{\left(P_{t}-\mu\right)+\frac{1}{n}\left(P_{j}-P_{j}^{-}\right)\right\}^{2}=\sigma^{2}+\frac{1}{n^{2}}\left(P_{j}-P_{j}^{-}\right)^{2}>\sigma^{2}
\end{gathered}
$$

if we notice that,

$$
\frac{1}{n}\left(\sum_{t=1, t \neq j}^{n} P_{t}\right)=\mu-\frac{P_{j}}{n}
$$

and then,

$$
\begin{aligned}
& \mu_{+}=\mu-\frac{P_{j}}{n}+\frac{P_{j}^{+}}{n}=\mu+\frac{1}{n}\left(P_{j}^{+}-P_{j}\right) \\
& \mu_{-}=\mu-\frac{P_{j}}{n}+\frac{P_{j}^{-}}{n}=\mu-\frac{1}{n}\left(P_{j}-P_{j}^{-}\right)
\end{aligned}
$$

Now it becomes easy to write the respective Sharpe ratios $S, S_{+}$and $S_{-}$in the absence of outlier, and in the presence of a positive and a negative outlier respectively.

$$
\begin{gathered}
S=\frac{\mu-r}{\sigma} \\
S_{+}=\frac{\mu_{+}-r}{\sigma_{+}}=\frac{\mu-r+\frac{1}{n}\left(P_{j}^{+}-P_{j}\right)}{\sqrt{\sigma^{2}+\frac{1}{n^{2}}\left(P_{j}^{+}-P_{j}\right)^{2}}}<S \\
S_{-}=\frac{\mu_{-}-r}{\sigma_{-}}=\frac{\mu-r-\frac{1}{n}\left(P_{j}-P_{j}^{-}\right)}{\sqrt{\sigma^{2}+\frac{1}{n^{2}}\left(P_{j}-P_{j}^{-}\right)^{2}}}<S
\end{gathered}
$$

Therefore, the bias implied by the existing outlier return relies strongly on the magnitude $d_{j}$ of this outlier, namely the difference $\left(P_{j}^{+}-P_{j}\right)$ or $\left(P_{j}-P_{j}^{-}\right)$. As a rough guide, we display in Table A1 the obtained Sharpe ratios for a varying outlier's magnitude when $\mu-r=5, \sigma=50$, the risk-free rate is $r=3$ and a sample size $n=65$. All the data under consideration are expressed on a percentage basis and on an annual basis.

According to Table A1, the magnitude $d_{j}$ of the outlier return drives the existence of an upward or a downward bias in the level of Sharpe ratio. We also plot such trade-off in the Figure A1 since the sample size also drives the systematic upward or downward bias for a given magnitude $d_{j}$. The simulation assumes a varying sample size $n$ when $\mu-r=5, \sigma=80$, the risk-free rate is $r=3$ and an outlier's magnitude $d_{j}=5$. All the data under consideration are expressed on a percentage basis and on an annual basis. 
Table A1

Impact of an Outlier Return on Sharpe Ratio

\begin{tabular}{rlllll}
\hline$d_{j}(\%)$ & $S$ & $S_{+}$ & $S_{-}$ & $S_{+}-S$ & $S_{-}-S$ \\
\hline 0.50 & 10 & 10.0142 & 9.9834 & 0.0142 & -0.0166 \\
1.00 & 10 & 10.0260 & 9.9645 & 0.0260 & -0.0355 \\
2.50 & 10 & 10.0472 & 9.8938 & 0.0472 & -0.1062 \\
5.00 & 10 & 10.0358 & 9.7317 & 0.0358 & -0.2683 \\
7.50 & 10 & 9.9688 & 9.5191 & -0.0312 & -0.4809 \\
10.00 & 10 & 9.8519 & 9.2637 & -0.1481 & -0.7363 \\
12.50 & 10 & 9.6924 & 8.9745 & -0.3076 & -1.0255 \\
15.00 & 10 & 9.4987 & 8.6605 & -0.5013 & -1.3395 \\
17.50 & 10 & 9.2788 & 8.3306 & -0.7212 & -1.6694 \\
20.00 & 10 & 9.0407 & 7.9925 & -0.9593 & -2.0075 \\
22.50 & 10 & 8.7911 & 7.6527 & -1.2089 & -2.3473 \\
25.00 & 10 & 8.5360 & 7.3165 & -1.4640 & -2.6835 \\
27.50 & 10 & 8.2798 & 6.9879 & -1.7202 & -3.0121 \\
30.00 & 10 & 8.0263 & 6.6698 & -1.9737 & -3.3302 \\
\hline
\end{tabular}

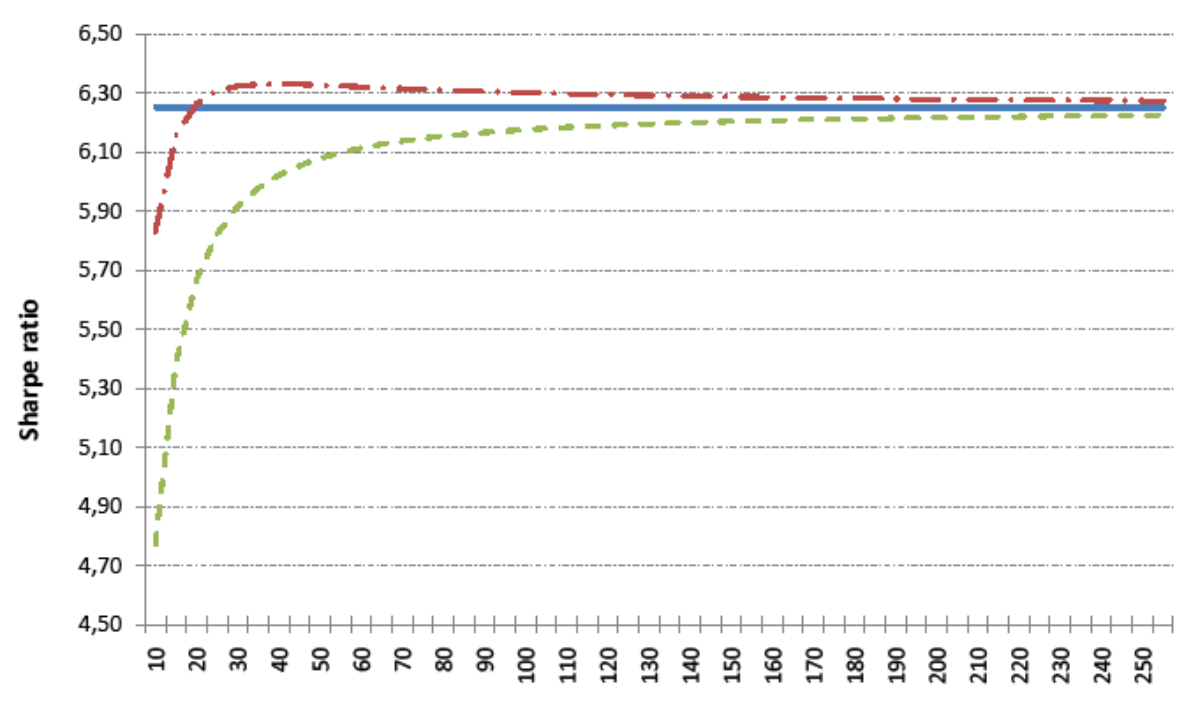

Sample size $n$

$-\mathrm{S} \quad-\cdot \mathrm{S}+\quad--\mathrm{S}-$

Figure A1. Sharpe ratios as functions of the returns' sample size.

The previous graph exhibits the systematic upward and downward bias in the Sharpe ratio's level relative to the existence of a positive and a negative outlier return respectively. Of course, such bias tends to disappear as the sample size grows rapidly. However, such features may not be negligible as the number of outlier returns increases. The accumulation of outliers generates an accumulation of outliers' respective magnitudes. Indeed, the magnitude's impact $d_{j}$ becomes $\sum_{j}\left(P_{j}^{+}-P_{j}\right), \sum_{j}\left(P_{j}-P_{j}^{-}\right)$or even $\sum_{k}\left(P_{k}^{+}-P_{k}\right)-\sum_{j}\left(P_{j}-P_{j}^{-}\right)$when there are many positive and/or negative outliers.

Non-parametric Correlation Matrix

We display in Tables A2 and A3 the Spearman and Kendall correlation coefficients between hedge fund index returns and market data returns. Observed nonparametric correlation coefficients are generally significant at a one or five percent bilateral student test level. 
Table A2

Spearman Correlation Coefficients

\begin{tabular}{lllllccc}
\hline DJHF index & DJIA & \multirow{2}{*}{ DJC } & \multirow{2}{*}{ SP500 } & DWCF & $\begin{array}{l}\text { Lehman } \\
\text { Agg.NAV }\end{array}$ & $\begin{array}{l}\text { Lehman } \\
\text { Comp. }\end{array}$ & $\begin{array}{l}\text { iBoxx IG } \\
\text { NAV }\end{array}$ \\
\hline SB_CA & $-0.2051^{* *}$ & $-0.2257^{* *}$ & $-0.2305^{* *}$ & $-0.2280^{* *}$ & $0.0748^{*}$ & 0.0506 & $0.1395^{* *}$ \\
SB_DS & $0.3703^{* *}$ & $0.3822^{* *}$ & $0.3913^{* *}$ & $0.4199^{* *}$ & -0.0462 & -0.0634 & -0.0315 \\
SB_ED & $0.7392^{* *}$ & $0.7455^{* *}$ & $0.7767^{* *}$ & $0.7986^{* *}$ & $-0.0923^{* *}$ & $-0.0860^{*}$ & $-0.0982^{* *}$ \\
SB_EMN & $0.1500^{* *}$ & $0.1730^{* *}$ & $0.1523^{* *}$ & $0.1515^{* *}$ & $-0.0965^{* *}$ & -0.0028 & $-0.0965^{* *}$ \\
SB_MA & $0.3974^{* *}$ & $0.4016^{* *}$ & $0.4282^{* *}$ & $0.4462^{* *}$ & $-0.0913^{*}$ & $-0.0972^{* *}$ & $-0.1243^{* *}$ \\
SB_ELS & $0.6887^{* *}$ & $0.7130^{* *}$ & $0.7528^{* *}$ & $0.7831^{* *}$ & $-0.1300^{* *}$ & $-0.1089^{* *}$ & $-0.1241^{* *}$ \\
BPI & $0.6451^{* *}$ & $0.6644^{* *}$ & $0.6888^{* *}$ & $0.7180^{* *}$ & $-0.1105^{* *}$ & $-0.0853^{*}$ & $-0.1051^{* *}$ \\
BPI_AX & $0.5403^{* *}$ & $0.5517^{* *}$ & $0.5657^{* *}$ & $0.5905^{* *}$ & $-0.0866^{*}$ & -0.0638 & $-0.0771^{*}$ \\
BPI_BX & $0.4930^{* *}$ & $0.5071^{* *}$ & $0.5189^{* *}$ & $0.5431^{* *}$ & $-0.0823^{*}$ & -0.0674 & $-0.0800^{*}$ \\
\hline
\end{tabular}

Notes. ${ }^{*} 5 \%$ significance level; ${ }^{* *} 1 \%$ significance level.

Table A3

Kendall Correlation Coefficients

\begin{tabular}{llllllll}
\hline DJHF index & DJIA & DJC & SP500 & DWCF & $\begin{array}{l}\text { Lehman } \\
\text { Agg.NAV }\end{array}$ & $\begin{array}{l}\text { Lehman } \\
\text { Comp. }\end{array}$ & $\begin{array}{l}\text { iBoxx IG } \\
\text { NAV }\end{array}$ \\
\hline SB_CA & $-0.1390^{* *}$ & $-0.1532^{* *}$ & $-0.1574^{* *}$ & $-0.1546^{* *}$ & $0.0513^{* *}$ & 0.0359 & $0.0959^{* *}$ \\
SB_DS & $0.2585^{* *}$ & $0.2672^{* *}$ & $0.2765^{* *}$ & $0.2974^{* *}$ & -0.0301 & -0.0418 & -0.0214 \\
SB_ED & $0.5574^{* *}$ & $0.5653^{* *}$ & $0.5990^{* *}$ & $0.6210^{* *}$ & $-0.0630^{* *}$ & $-0.0582^{*}$ & $-0.0663^{* *}$ \\
SB_EMN & $0.1015^{* *}$ & $0.1186^{* *}$ & $0.1045^{* *}$ & $0.1037^{* *}$ & $-0.0651^{* *}$ & 0.0019 & $-0.0643^{* *}$ \\
SB_MA & $0.2782^{* *}$ & $0.2813^{* *}$ & $0.3032^{* *}$ & $0.3169^{* *}$ & $-0.0617^{* *}$ & $-0.0666^{* *}$ & $-0.0823^{* *}$ \\
SB_ELS & ${0.5073^{* *}}^{* *}$ & $0.5314^{* *}$ & $0.5702^{* *}$ & $0.6005^{* *}$ & $-0.0880^{* *}$ & $-0.0735^{* *}$ & $-0.0828^{* *}$ \\
BPI & ${0.4752^{* *}}^{* *}$ & $0.4927^{* *}$ & $0.5193^{* *}$ & $0.5461^{* *}$ & $-0.0750^{* *}$ & $-0.0578^{*}$ & $-0.0711^{* *}$ \\
BPI_AX & ${0.3903^{* *}}^{* *}$ & $0.3985^{* *}$ & $0.4140^{* *}$ & $0.4338^{* *}$ & $-0.0592^{*}$ & -0.0436 & $-0.0522^{*}$ \\
BPI_BX & $0.3563^{* *}$ & $0.3670^{* *}$ & $0.3782^{* *}$ & $0.3969^{* *}$ & $-0.0557^{*}$ & -0.0453 & $-0.0533^{*}$ \\
\hline
\end{tabular}

Notes. ${ }^{*}$ 5\% significance level; ${ }^{* *} 1 \%$ significance level. 